This item is the archived peer-reviewed author-version of:

Drivers of institutional innovation in networks : unleashing the innovation potential of domesticated markets

\title{
Reference:
}

Van Bockhaven Wouter, Matthyssens Paul, Vandenbempt Koen.- Drivers of institutional innovation in networks : unleashing the innovation potential of domesticated markets

Journal of business and industrial marketing - ISSN 0885-8624 - 30:3-4(2015), p. 414-435

DOI: http://dx.doi.org/doi:10.1108/JBIM-10-2013-0220

Handle: http://hdl.handle.net/10067/1239360151162165141 


\section{DRIVERS OF INSTITUTIONAL INNOVATION IN NETWORKS: UNLEASHING THE INNOVATION POTENTIAL OF DOMESTICATED MARKETS}

Purpose: Aiming to explain how network-level agency can innovate business fields, this paper explores the effectiveness of innovation networks (IN) when they address field-level challenges, besides generating product innovations. It starts from innovation networks as loci for open innovation and introduces the institutional innovation networks (IIN) concept to extend IN research toward the achievement of innovations that radically impact field-level outcomes like industry setting and logic. It studies the configurational characteristics and institutionalizing practices that allow IIN to achieve their field-level goals and separate them from regular IN, and what makes them successful at this task.by examining 3 differentially successful IIN. The study extends IN theory toward innovation realization in domesticated contexts. In such contexts, IN's success depends on their capacity to transform the business field in which they are embedded, so that it enables innovative ways of creating end-customer value.

Approach: Based on an embedded case study in the Dutch steel industry, we suggest a framework offering qualifying characteristics and success factors for the effectiveness of institutional innovation networks (IIN). The case builds on 26 semi-structured interviews and 4 focus groups with top managers. Aiming to extend mechanism-based explanations of innovation networks to an under-researched context, we adopt an abductive approach to theorizing, producing a more iterative, theory-laden process and paper than in purely inductive studies.

Findings: Our findings suggest that collaborating to collectively redesign an institutionalized business field implies explicit attention to interdependencies within that field. It requires configurations that subtly violate the small-world characteristics of innovation networks to incorporate critical mass, goal alignment efforts and a focus on common resource creation. Factors like inclusion of all relevant value chain actors, broad framed goals to attract all the necessary actors combined with sufficiently specialized initiatives, and a goal-appropriate mix of bottom-up, heterogeneous and collaborative characteristics to enable exploration with the centrality, proximity and competitiveness in other dimensions to ensure exploitation, are also key to IIN success.

Implications: Besides suggesting a new area for theorizing about innovation networks, IIN are also a useful template for institutional innovation and collective action research. The paper offers a framework to support managers in the largely ignored challenge of developing a collective action network. In an increasingly transparent, connected and consolidated business environment, such a challenge becomes ever more essential.

\section{INTRODUCTION}

According to IBM's 2012 global CEO study, market leaders are 28\% more likely to partner with other firms for innovation. Not surprisingly, recent years have seen an upsurge in attention to innovation networks (further IN) in managerial and scholarly literature on open innovation, industrial networks, cocreation and interorganizational learning. IN have been found to stimulate learning (Powell et al., 1996), complex innovations (Rycroft \& Kash, 2004), business model reconfiguration (Calia et al., 2007), sales growth and innovation rates (Stuart, 2000). Their competitive effectiveness is positively influenced by previous collaboration experience of the partners, access to external knowledge (Cowan et al., 2007), trust among members (Levin \& Cross, 2004), knowledge mobility (Dhanaraj \& Parkhe, 2006), networking competence (Ritter \& Gemünden, 2003), absorptive capacity (De Jong \& Freel, 2010) of each party, innovation competence and relational risk governance (Gilsing \& Nooteboom, 2005). Extant literature thereby predominantly focuses on the management of knowledge flows, resources and relationships in an existing network for the effective creation of market offerings.

Despite widespread enthusiasm, the practice of innovation in collaborative networks has not spread equally in all industrial sectors. In fact, it appears to remain hard to implement or often unsuccessful in 
certain 'domesticated' markets (Arndt, 1979), in which innovation is significantly hindered by structural inertia. Markets are domesticated when the perfect competition mechanisms of 'traditional' marketing (Easton \& Araujo, 1994) are offset by longstanding arrangements and relationships. Exchanges are internalized within captive ties between network actors, to reduce uncertainty, transaction costs or for the synergy of combining complementary operations. Companies are seen as extensions of each other, and relations administered rather than competed for. This internalization of supply chain relations hinders the internal heterogeneity (Corsaro et al., 2012a) and access to external knowledge (Cowan et al., 2007) driving the success of IN. In such a context innovators would thus have to explicitly redesign the rigid, institutionalized market structures in which they are embedded - and held back by (Seo \& Creed, 2002). Such institutional entrepreneurship combines regular innovation with a specific focus on redesigning the collective business model ${ }^{1}$ and the institutional arrangements of an organizational field (Battilana et al., 2009). It is driven by deinstitutionalization pressures that delegitimize existing modes of exchange and it therefore induces agency that is explicitly oriented at field-level change.

Notwithstanding their intentional character (Möller \& Svahn, 2009; Rampersad et al., 2010), little research has studied how IN can be effective in overcoming institutional barriers to innovation like in domesticated contexts. We explore how the redesign of domesticated markets can be realized through IN. Our explanation thereof is aided by a supplemental neo-institutional lens, which is valuable because of its focus on (a) collective action (Astley \& Van de Ven, 1983), (b) consideration of a wide set of stakeholders, (c) social construction of new templates and (d) the interaction between contextual and actionable levels of analysis. It is a fitting basis to explain network innovation in a domesticated context, in which change is by necessity collective, frame breaking and involving the innovation at the business field level. As such, we aim to explain (Ryan et al., 2012) when innovation necessitates a teleological, collective and social-structural renewal of existing templates (Hargrave \& Van de Ven, 2006), what are then the drivers of success for innovation networks. More specifically, the research eventually came to focus explicitly on qualifiers and success factors of collective action through IN, and thus on following research questions:

(1) "what differentiates networks with a collective finality from typical IN?" and

(2) "what causes the performance differences among them?"

To this end, we examine three networks in the Dutch steel industry, where deinstitutionalization of its production-push model creates a sense of urgency among players in the middle of the chain to innovate their field. These networks' finality to perform business model innovation on a field-level makes them a special kind of IN. We examine how their configuration and the specific practices they employ to reinstitutionalize a new collective business model drive their institutional effectiveness. Our analysis focuses on the building blocks that differentiate these networks from regular IN and on the success factors that differentiate the more successful of these networks.

The study follows an abductive design, which has implications for how the paper is structured. First, it reviews extant literature on open innovation structures operationalized as networks and how these can contribute to the execution of institutional innovation. This literature review results in an initial analysis frame to be abductively triangulated with the data, making it slightly thicker than in typical inductive papers. The method section pays explicit attention to reporting the (critical realist) epistemological characteristics of the study. The findings section is also structured somewhat atypically. As guidance for and examples of abductive case studies are sparse, we follow the structure proposed by Ryan, Tähtinen, Vanharanta and Mainela (2012). It starts with a flat description of the case context and key network features and events. The subsequent analysis and interpretation sections respectively report the identification of causal mechanisms through triangulation and abstraction (Van Bockhaven et al., 2013) and how these mechanisms combine into an explanation of the phenomenon studied. The interpretation

\footnotetext{
${ }^{1}$ Here adopted similar to Battilana, Leca and Boxenbaum (2009) as a dominant organizational template in a field with respect to the way firms create value and compete; similar to what has been labeled an 'industry recipe'.
} 
introduces additional literature to fill explanatory gaps in the initial analysis frame, echoing the abductive process of systematically combining theory and empirical data for the most plausible explanation (Dubois $\&$ Gadde, 2002). Specifically, social movement mechanisms, commonly used to explain dialectical change processes in institutional entrepreneurship (Hargrave \& Van de Ven, 2006), emerged as relevant. The paper concludes by assessing the theoretical and practical implications.

\section{LITERATURE \& CONCEPTUAL MODEL}

\subsection{INNOVATION NETWORKS: TEMPLATES FOR OPEN INNOVATION AND MORE}

In innovation management literature, it is commonplace to study innovation as a collaborative enterprise. This has spawned a large body of literature on open innovation. As this stream approaches open innovation predominantly from a firm or dyadic perspective (West et al., 2006), it leaves two gaps that can be addressed by taking a network perspective. First, despite recent work investigating the impact of size and centralization (Pisano \& Verganti, 2008), climate and processes (Enkel et al., 2011) and organizational forms (Bianchi et al., 2011), traditional open innovation literature lacks a systematic treatment of how to organize for open innovation. Second, it lacks a critical assessment of barriers to open innovation outside the dyad or the corresponding strategies to address them.

Regarding the first gap, IN explicate the relevant locus of innovation (Powell et al., 1996), embracing the open innovation paradigm (Chesbrough, 2003). This literature conceptualizes open innovation systems as low-density, self-organizing (Rycroft \& Kash, 2004), yet loosely orchestrated (Dhanaraj \& Parkhe, 2006) networks with an explicit aim of acquiring and recombining complementary knowledge (Cowan \& Jonard, 2009) for complex innovations (Rycroft, 2007). It also provides a more detailed conception of collaboration form types (Möller et al., 2005), how they facilitate knowledge exploitation, exploration and recombination (Rycroft \& Kash, 2004; Dittrich \& Duysters, 2007) and how their birth and further development can be influenced (Möller \& Svahn, 2009; Dhanaraj \& Parkhe, 2006).

By providing a template to study open innovation, IN literature also addresses the second gap, pertaining to the higher-level challenges that IN allow to address (Dhanaraj \& Parkhe, 2006) and the contingent approaches they require. Predominantly approached from a technological systems perspective, IN literature provides insights on the impact of technological and competitive challenges (Dittrich \& Duysters, 2007; Pyka \& Küppers, 2002; Rycroft, 2007). Yet, it hardly addresses the institutional pressures affecting an organizational field. This is peculiar, because many IN have an explicit reference to institutional challenges in their mission statement, so it would make sense to study their effectiveness in attaining these institutional goals. In fact, whether intended or not, collaborative networks have the potential to induce field-level change through the creation of new institutions, such as new modes of exchange and collaboration (Lawrence et al., 2002). Nonetheless, IN are mostly approached as new product development networks which combine knowledge and resources to develop and diffuse complex products or product platforms (Pyka \& Küppers, 2002; Rycroft \& Kash, 2004). IN literature provides evidence for factors affecting innovative and commercial value creation (Corsaro et al., 2012b), strategic adaptation (Dittrich \& Duysters, 2007) and member perceptions of effectiveness (Rampersad et al., 2010). Yet, the effectiveness in achieving goals at the field level, such as stimulating innovation in an inert industry, improving its competitive position versus growing substitutes, or increasing its geographical or political reach, are rarely discussed.

This paper looks into this underexplored institutionalizing role of networks and provides exploratory insights in what makes them effective in performing it. It aims to enrich IN literature with the multilevel institutional mechanisms turning meso-level collective action into field-level institutional change (Purdy \& Gray, 2009; Hargrave \& Van de Ven, 2006). This combination of theories is not entirely new as institutional factors, like a high need for structural embeddedness (Cowan et al., 2007) or institutional misfit (Van Bockhaven et al., 2013) motivate the emergence of IN. Both streams' explanations of change furthermore share an underlying systems perspective, but at different levels of aggregation (Dhanaraj \& 
Parkhe, 2006; Scott, 2008; Rycroft \& Kash, 2004). IN are small worlds ${ }^{2}$, a specific type of institutional network arrangement that is a subset of the interorganizational network comprising the whole field (Kenis \& Knoke, 2002; Baum et al., 2003). Unlike such field-nets, IN consist of a proactive set of organizations joined intentionally to achieve predefined innovation outcomes.

\subsection{INNOVATION IN NETWORKS AS INSTITUTIONAL CHANGE}

Innovation begets a collective and intentionally frame-breaking character in contexts marked by high ex ante rigidity. In such contexts, change is restrained by institutionalized barriers and can only occur once sufficient momentum is built-up (Greenwood \& Hinings, 1996). By definition, innovation in domesticated markets is thus more in line with an institutional than an agency model of innovation and change (Arndt, 1979). Such institutional innovation is triggered by a process of deinstitutionalization, in which the old rules of the game become obsolete and dissipate due to political, social or functional pressures (Oliver, 1992). As the existing arrangements become obsolete, innovation is initiated by entrepreneurial insurgents who are dissatisfied with the existing arrangements (Greenwood \& Hinings, 1996) and have an interest in developing new ones (Dimaggio, 1988).

Framed in an evolutionary focus on strategic fit (Beer et al., 2005), institutional innovation can focus on the industry's market offering, its administrative or technological processes or on its market structure, wherever misfit resides. It follows a dialectic pattern where the deinstitutionalization of the old arrangement leads to the reinstitutionalization - the theorization, legitimation and dissemination - of a new 'template' (the organizational configuration of a set of firm- or network-level processes or even the business model as a whole) (Hinings et al., 2004). Achieving reinstitutionalization requires a new arrangement to better accommodate stakeholders' interests as well as their shared commitment to the values of the new template (Greenwood \& Hinings, 1996).

This paper looks more closely into the transition from deinstitutionalization to reinstitutionalization. The old dissipating structures leave a vacuum that acts as a burning platform driving the search for new ones. By intentionally trying to replace the old institutional arrangement with a new one, actors engage in institutional entrepreneurship. This means that they will actively mobilize resources and other actors to change the very institutional arrangement they are cognitively, normatively and regulatively conditioned by (Seo \& Creed, 2002; Dimaggio, 1988). Such entrepreneurship driven by the deinstitutionalization of old templates is often represented as being initiated and driven by entrepreneurial individuals (Dimaggio, 1988). This attracted critiques about the ambiguity of the concept's level of analysis, as it entails an inherently collective activity (Battilana et al., 2009). As such, we examine the extent to which our institutional lens on IN as a network-level construct captures both the agency of institutional entrepreneurs and the collective nature of the activities involved.

\subsection{REINSTITUTIONALIZING THE INNOVATION: PRACTICES AND TEMPLATES}

Institutional innovation specifically encompasses field-level precipitating dynamics and outcomes, yet we zoom in on the black box of institutional entrepreneurship dynamics in networks. So although section 4.1 describes the specific domesticated case context prompting institutional agency, the focus further on is clearly on unpacking the mechanisms that enable effective reinstitutionalization. Thus, our initial conceptual model focuses on the specific tactics to collaboratively reinstitutionalize a new field-level template. As "institutionalization is both a process and a property variable" (Zucker, 1977), we thereby focus on the reinstitutionalization practices and institutional templates. The former relate to the specific institutional entrepreneurship actions that differentiate these networks from regular IN. The latter entail the configuration of design choices which determine the eventual IN's capacity to address the challenges threatening the entire field. We assess the institutional effectiveness of these elements in terms of innovation output and market acceptance, which both contribute to the networks' impact on the field.

\footnotetext{
${ }^{2}$ They match the criteria of sparseness in terms of density, asymmetry in terms of centrality, local clustering and a low diameter in terms of reachability (Cowan \& Jonard, 2009).
} 
These outcomes are measured in three Dutch steel industry networks with an explicit higher-order mission.

Before these case networks are studied, we first review the practices and configurational factors that purportedly determine the effectiveness of innovation networks and institutional entrepreneurship. This initial analytical frame (Figure 1) guided the first phase of our fieldwork, which then serves as 'inspiration' (Siggelkow, 2007) on how IN help achieve institutional entrepreneurship. The case explores the black box regarding the specific elements differentiating these networks from other IN and the network effectiveness implications of attempting institutional entrepreneurship.

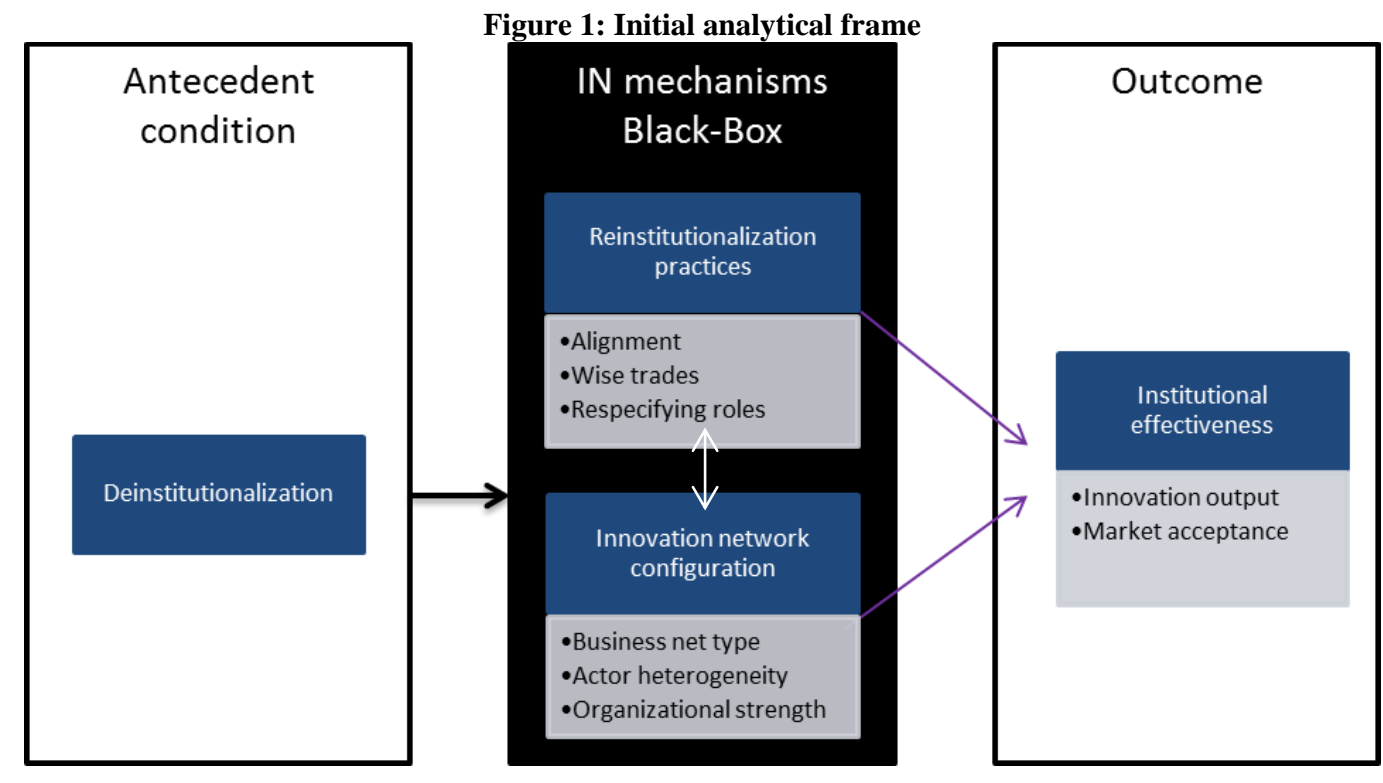

\subsubsection{Opening the institutional effectiveness black box for innovation networks}

\subsubsection{Reinstitutionalization practices}

The institutional entrepreneurship process is all about overcoming cognitive, normative and regulative barriers blocking reinstitutionalization through issue framing and the mobilization of actors and resources. The practices to overcome these barriers can be divided into three phases (Veal \& Mouzas, 2010). First, the initiating firm(s) need(s) to frame the strategic marketing vision behind which they want to mobilize partners. In this phase several cognitive mechanisms might interfere with the adoption of collaborative behavior by either blocking full recognition of the value of the strategic initiative or by triggering a noncollaborative mindset and action repertoire. Related to this challenge, industrial networks scholars have elaborated the need to align actors' frames (Corsaro \& Snehota, 2011), as co-evolution should not be taken for granted in cases of radical innovation (Matthyssens et al., 2009).

Second, after actors agree in principle to address a common issue, they negotiate the terms of the collaboration process and the value appropriated. In this phase, they are required to 'see the bigger picture' to overcome short-term or zero-sum reflexes that prevent the realization of mutual wins. Potential solutions are mobilizing based on higher-order moral values (Ritvala \& Salmi, 2010), or expliciting interdependencies in network pictures (Henneberg et al., 2006) to recognize longer term interests. Third, if actors do succeed in making 'wise trades' (Veal \& Mouzas, 2010), they might still run into boundary disagreements about the network's focal points and its temporal or technical reach. This requires the development of adequate collaborative structures to vision boundaries and re-specify actor roles (Möller $\&$ Svahn, 2009). In going from the deinstitutionalizing value chain to the new issue-based value system 
and then again to a new vertical value chain, actors face different functional role demands, requiring varied capabilities and coordination structures.

\subsubsection{Innovation network configuration}

Regarding the design of the collaborative infrastructure, the study builds on prior work on business net types, participating actor heterogeneity and the net structure. Previous research shows that end user value is created mainly at the network level and that network configurations substantially affect it (Corsaro et al., 2012b). A comprehensive assessment of configurational characteristics of IN distinguishes different business net types based on actors' goals, goal unity, the actor structure, breadth of the activity set, technology range, the network development process, power distribution and planning horizon (Möller et al., 2005). The structural aspects of network configurations are further divided into the pattern of different actor roles in the network and the intensity of interactions between them (Gemünden et al., 1996), which we conceptualize as respectively heterogeneity and organizational strength below.

On heterogeneity, IN and institutional literature have similar findings recommending respectively an optimal degree of distance (Cowan \& Jonard, 2009) and an optimal degree of embeddedness (Uzzi, 1997). However, operationalizing actor diversity indiscriminatingly renders equivocal findings on innovation performance (Goerzen \& Beamish, 2005). So, IN scholars recommend a multidimensional view of actor proximity and heterogeneity. Knowledge exchange and goal convergence in networks have been found to benefit from geographical, cognitive, vision and technological proximity, (Cantù, 2010). On the other hand, heterogeneity benefits IN performance in terms of complementary knowledge and capabilities, and of diversity in perceptions, culture and power (Corsaro et al., 2012a; Cowan et al., 2007). These distinctions go beyond technical-functional factors and also make a case for diversity in the cognitivecultural and normative institutional dimensions (Scott, 2008).

\section{METHOD}

\subsection{EPISTEMOLOGICAL POSITION}

The aim of our case study, in line with the abductive approach and the critical realist epistemological position underlying it, is to abstract mechanism-based explanations of a phenomenon (i.e. the effectiveness of innovation networks which have an institutional finality as well as a commercial one). In line with Sayer (1992), these explanations take the form of identifying the mechanism, describing the way it works, illustrated by the case and suggesting liabilities and conditionalities based on the deep empirical understanding from the case-study. Reporting these abductive, theory-laden inferences in the format expected in a journal article, which promotes either inductive or deductive designs, is not a sinecure. The complex nature of the research problem means that elements from many of the conceptual frames employed were found useful for further interpretation. So the paper risks coming across as deductive, while the framework that seems to be tested is in fact to a high degree selected over several iterations and shaped by the data. Focusing on mechanism-based explanation, we introduce the theoretical rationale for the concepts found to be important in the literature section, as in a traditional (deductive) paper and let the results deal with how these mechanisms were found to work in the empirical case. Although it appears strange to infuse that conceptual and theoretic body in the results, it helps differentiate our contribution from what we took as initial analytical frame.

Aiming to extend theory, this goes further than describing a specific event or occurrence in its context or than merely identifying new concepts. The critical realist epistemological position thereby differs from the constructivist preoccupation with accurate description of contextualized events or the positivist focus on prediction. This alternative approach to case study method is now more explicitly presented in in industrial marketing and management literature (Easton, 2000; Ryan et al., 2012; Van Bockhaven et al., 2013). Due to a lack of actually executed examples of such critical realist inspired abductive case-studies, we adopt the approach by Ryan and colleagues (2012). Section 3.4 furthermore explains how abductive theorizing enabled analytical generalization of the case findings into a mechanism-based explanation. 


\subsection{RESEARCH DESIGN}

This study builds on a single embedded case study of three innovation networks within the same spatiotemporal context of the Dutch steel industry. All three networks have a joint origin in the SFN federation, the general representing body of the distributors and service centers in the middle of the Dutch steel chain. SFN is a driving force behind programs addressing the deinstitutionalizing challenges facing these SMEs. Its management identified the three networks in a focus group as being explicitly oriented at tackling these challenges, with different levels of success. The three focal networks are thus embedded units of agency for a field-level problem. Such an embedded case study (Yin, 1984) has two important advantages over a multiple case study (MCS) for our purpose. First, to achieve analytical generalization, based on replication logic like experimental research, embedded case studies are preferable over MCS designs. For an experiment, it is preferable to control as much as possible potential confounders on the mechanisms under study. Although case study researchers attempt to do so, they analyze contexts which are inherently multifaceted and complex (von Krogh et al., 2012), where any number of confounders might play. Some can perhaps not even be recognized, given the prevailing state of knowledge. In a single embedded case study, the different subunits share a large number of contextual influences relating to both the business context and the change event. Hence, the breadth of real contingencies differentiating between the different subunits becomes more identifiable and controllable.

Second, in a revelatory case (Yin, 1984), which is contrasted with a 'normal' situation, multiple subunits embedded within the same context allow more accurate generalizations of a specific causal configuration of a mechanism with its operant conditions and liabilities (Sayer, 1992). Where a MCS is specifically designed to identify constant patterns in different contexts, the contextual homogeneity of embedded cases allows a more tightly focused abstraction of the mechanism itself and a limited set of contingencies from empirical observations. Embedded cases allow peeling-off different layers of actualized and subjective confounds (Harrisson \& Easton, 2004; Grünbaum, 2007) from the causal mechanisms, rather than equating them with the constant conjunction of observed outcomes (Tsoukas, 1989).

Hence, we argue that the robustness of analytical generalization about specific causal mechanisms is better served by making more iterations in abductively contrasting and refining explanations within one context, than by repeating the analysis in different ones. With equal resources and time allocated to two research projects, embedded case studies can be more elaborately contextualized, thereby going in depth on the interpretations and assumptions of actors to rule out spurious causations. Given that social contexts are never entirely knowable, analytical accuracy of theoretical inferences from a single embedded case study should be higher than that of a comparable MCS due to economies of scope. By advancing the spread of cases over their analytical depth or contextualization, Yin's notion of robustness sacrifices analytical generalization for the sampling logic of statistical generalization. So MCS are recommended when the mechanism's sensitivity to contextual cues is subject of inquiry. A rich single embedded case, however, is preferable when a deeper understanding of the causal configuration itself is explored in the first place.

\subsection{DATA COLLECTION AND ANALYSIS}

Data collection occurred from 2010 through 2012 in two stages in the Dutch steel industry. Arndt (1979) explicitly refers to the European steel chain as prototypically domesticated already in the seventies and its business model did not change by much in the following three decades. As such, it is a highly suited, even extreme empirical context to learn about strategies to overcome inertia. In stage 1 (Figure 2), ethnographic immersion was obtained through previous and ongoing applied research in and for the industry. This stage further served to focus attention as to where and how the empirical case could result in a theoretical contribution. It produced the selection of the theoretical concepts in the initial analytical frame in figure 1. The focus groups in this stage complemented the interviews to test our interpretations of trends in the industry and their potential drivers with theories and expert interpretations in interviews and focus groups. This enabled causal inference through triangulation of different respondents and data sources which validate and enrich each other's explanation (Ryan et al., 2012). 
Figure 2: Stages, data collection methods and topics of the abductive research process
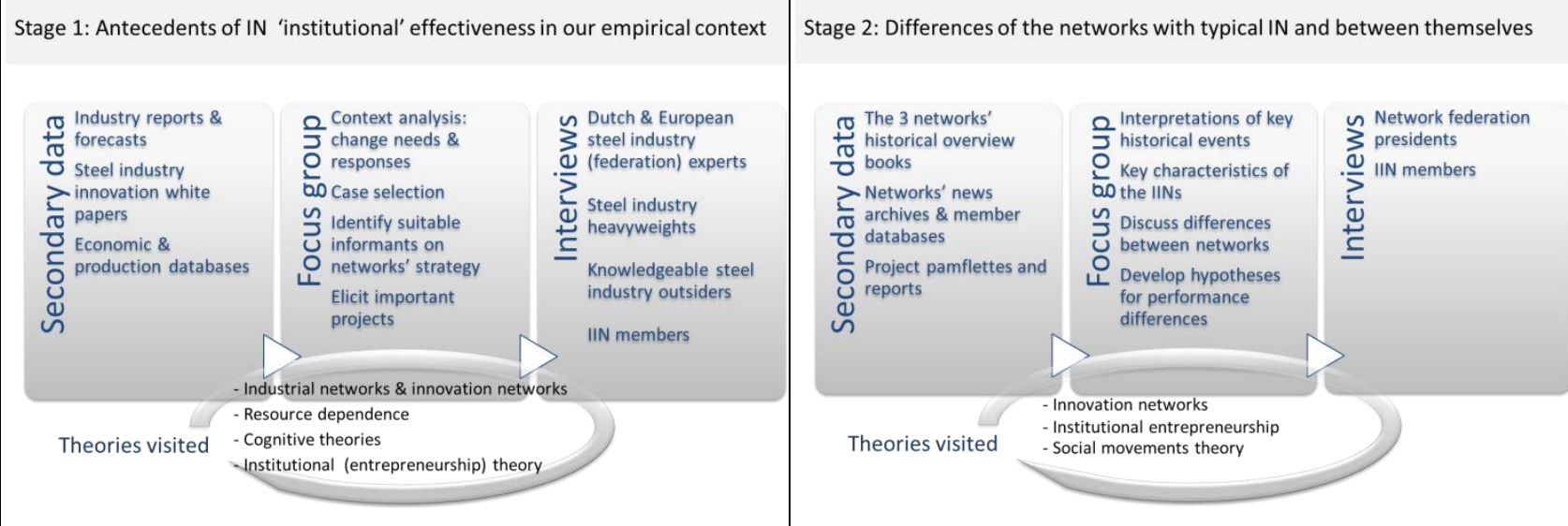

The second stage continued this abductive process of constant comparison (Dubois \& Gadde, 2002) and helped discern exactly how our findings extend IN literature. It led to a further division of our analytical frame's dimensions by seeking to answer the overall research question separated into (1) what differentiates these networks from typical IN and (2) what causes the performance differences among them. It focused on three initiatives spearheading the field's renewal as 'horizontal' networks that, unlike vertical supply chains include complementary producers and direct competitors (Möller et al., 2005). They are considered as IN with an institutional finality as they were aimed not only to stimulate product or process innovations, but to address certain higher-level challenges which required the steel chain to innovate its domesticated structures as well. We argue that such networks are quite unique as well. Cases exist of networks aimed at field-level public good creation for social-environmental causes (e.g. Ritvala \& Salmi, 2010). Yet, to our knowledge IN and institutional entrepreneurship literature describes little examples of networks aiming to 'educate' and promote the competitiveness of an entire business market.

Data sources consisted of industry-specific document analysis, 26 semi-structured interviews, 4 focus groups and participation in conferences of the industry. The secondary documents served as an initial basis to develop interpretations of events, which we summarized in intermediate reports. These reports were then discussed in the focus groups, so as to contrast our interpretations and elicit those of the industry experts. The semi-structured interviews lasted between 45 and 100 minutes. Telephonic interviews were audio recorded and annotated. Depending on the expertise of the informant and the stage of the research, the interviews revolved around specific concepts mentioned in Figure 1. In stage 1, these could revolve around the perceived effectiveness and deinstitutionalization pressures needing to be addressed with downstream network members. In stage 2, they treated e.g. the specific configurational aspects and goals with the networks' management or the practical perceptions of what did and did not work in projects with members. Informants were top managers from representative firms throughout the steel chain ${ }^{3}$, most of which were engaged in at least one of the three network federations or in the associated steel chain's midstream industry association. Three respondents were the current presidents of the network federations under study. Focus groups of minimally two hours were dual moderated (Morgan \& Krueger, 1998) and contained subsequent exploratory, experiential and clinical phases (Fern, 2001) to generate and debate opinions and elicit underlying rationales. They were very helpful to triangulate previous findings and uncover hidden agendas, as were the informal conferences we attended. To counter retrospective bias, the findings on the networks' history were either based on or validated with the internal news archives, as well as historical overview books published at the event of a jubileum of the network. Moreover, the risk of retrospective bias is in this case mitigated because the founding events asked for were quite important (Akerlof \& Yellen, 1985) and requested information was predominantly of an objective nature.

\footnotetext{
${ }^{3}$ Except iron ore miners; see Appendix A for a more detailed overview.
} 
Data analysis occurred through a mixture of content analysis and elements of discourse analysis. All interviews were summarized right after they took place to allow for an immediate identification of themes in the data, resulting in the first-order codes of our content analysis ${ }^{4}$. The abductive inference process is notably iterative and the content analysis thus involves an ongoing combination of the analysis frame, empirical data and potentially new theories to triangulate and match better fitting explanations (Dubois \& Gadde, 2002). Further hierarchical codes and revisions of initial codes resulted from this process as suggested in (Van Bockhaven et al., 2013). So, records of the interviews and the respondents were kept, so that in some cases respondents could be contacted for further clarification after new, contrasting data emerged. Elements of discourse analysis were adopted to peel-off subjective impressions from objective cores (Harrisson \& Easton, 2004) by contrasting interviews with written sources and by the way interviews were conducted as well. Although starting from a minimally defined topic list, the semistructured interviews started from broad questions to allow ample freedom to the respondents so as to enable a discourse analysis. This enabled us (1) to contrast subtle differences in how different respondents construed events or perceptions of network factors and (2) to elicit emerging factors or issues. The emerging issues and intrasubjective elements from the discourse analysis fed back into the content analysis as open codes, which combined with the selective coding (Shepherd \& Sutcliffe, 2011) from the more expected or theoretically explainable codes into the abductive analysis.

\subsection{THEORIZING APPROACH}

Theorizing adhered to the abductive process due to an explicit ambition to abstract generalizable mechanism-based explanations from our data by contrasting it with theoretical predictions and then reconstructing the theoretical frame to accommodate anomalies. Like the inductive top-down approach to theorizing (Shepherd \& Sutcliffe, 2011), it starts from the data to direct attention for the development of an interpretive frame (Matthyssens \& Vandenbempt, 2003) that captures what is currently known in the literature. This is for example why the sampling approach and the analytical frame followed from the empirical context, rather than a predetermined theory.

Unlike the inductive top-down approach, pure abduction starts from an ontological research problem (Easton, 2000) and thus from empirical rather than 'theoretical data' (Shepherd \& Sutcliffe, 2011). The choice of theories and the factors in our analytical frame were guided by an earlier phase of ongoing research and consulting in the Dutch steel chain. The goal of this frame then is not to fit data within predetermined theoretical categories to deductively test their relation, but to identify and refine an analytical frame that offers the most fitting explanation of the phenomenon observed (Ryan et al., 2012; Van Bockhaven et al., 2013). From there, the researcher inductively further refines this frame to extend rather than test theory, as the case data in the second stage served as 'inspiration' (Siggelkow, 2007) for mechanisms underlying unexplained phenomena in that theory.

The only elements of our analytical frame that were fixed a priori, are the antecedent condition of deinstitutionalization, which is exogenous to the actual model, and the outcome, which was also present in sampling the three differentially effective networks. Market acceptance, measured as the percentage of targeted actors involved in the network, is taken to represent its reach among stakeholders. This is consistent with social movement theory ${ }^{5}$, according to which a movement's effectiveness in changing

\footnotetext{
${ }^{4}$ Stored in a mindmapping software, to increase coding flexibility as well as the ability to draw and change relations quickly.

${ }^{5}$ It was in the first phase of our research in combination with the SFN federation that we learnt about different networks as answers to the macro challenges the industry was facing. Based on impressions from earlier talks with managers, we already knew that the perceived performance of BwS was greater than that of the SSTM and much greater than that of FMS. As we did not want to trust only on these perceptions, when we actually developed our conceptual frame in stage 1, we measured objective performance in two ways. The early conjectures about the networks' performance, which guided our sampling, were confirmed in the empirical work of phase 1.These proxies followed our initial theoretical frame and were later also confirmed as relevant measures as we turned to social movement theory.
} 
policy or the institutional environment is primarily determined by the resonance of its frame (Benford \& Snow, 2000). Another outcome measure, innovation projects, measures the proportion of projects rated 'radical' and 'widely successful' by experts. This output measure is in a sense more traditional to innovation literature, yet also a proxy for the success of institutional entrepreneurship as it also incorporates the diffusion of the innovation and thus its field-level impact. As the institutional entrepreneur seeks to redesign institutional arrangements to enable new value creation in line with environment demands (Cantwell et al., 2010), the number of successful radical innovations can be seen as a proxy of effectiveness in winning through institutional barriers.

\section{CASE DESCRIPTION}

\subsection{CONTEXT}

The Dutch steel chain has traditionally been a highly stable environment, protected by high reputational entry barriers. The pace of the industry was regulated by the large multinational steel producers, which determined the industry's price and volumes in an oligopolistic model. To this end, they also controlled the distribution chain by only delivering to fixed local wholesalers and service centers. In the last decade, however, Tata Steel's acquisition of Europe's major producer Corus in 2006 symbolized the steel market becoming more global and open to new players.

As production capacity outside Europe grew rapidly and European demand steadily declined, overcapacity and a weak global position put the industry's 'production push' business model under untenable pressure. On a socio-economic and technological level, downstream markets had also gotten alienated from that industry model, which did not meet their more advanced demands. In many end-markets one or more tiers of submodule suppliers and system integrators had been positioned between the steel chain and the OEMs. In fact, OEMs increasingly sought to substitute metal components by more innovative products. As a result, the conservative steel industry was losing ground to the concrete and plastics industries. Steel intensity in the Dutch industry steadily decreased by on average 4\% annually. As these downstream players thus became more critical towards the value created by the steel chain, the business model became unstable. Players in the steel chain hence became increasingly aware that their environment was less and less protected from outside pressures. Figure 3, presented at one of the industry's conferences in 2010, shows a rudimentary scheme of how industry executives tried to make sense of their supply chain (up-, mid- and downstream) and the outside pressures (above the chain) and related stakeholders (below) affecting it.

Figure 3: Diagnostic frame of the Dutch steel industry: supply chain and external stakeholders 


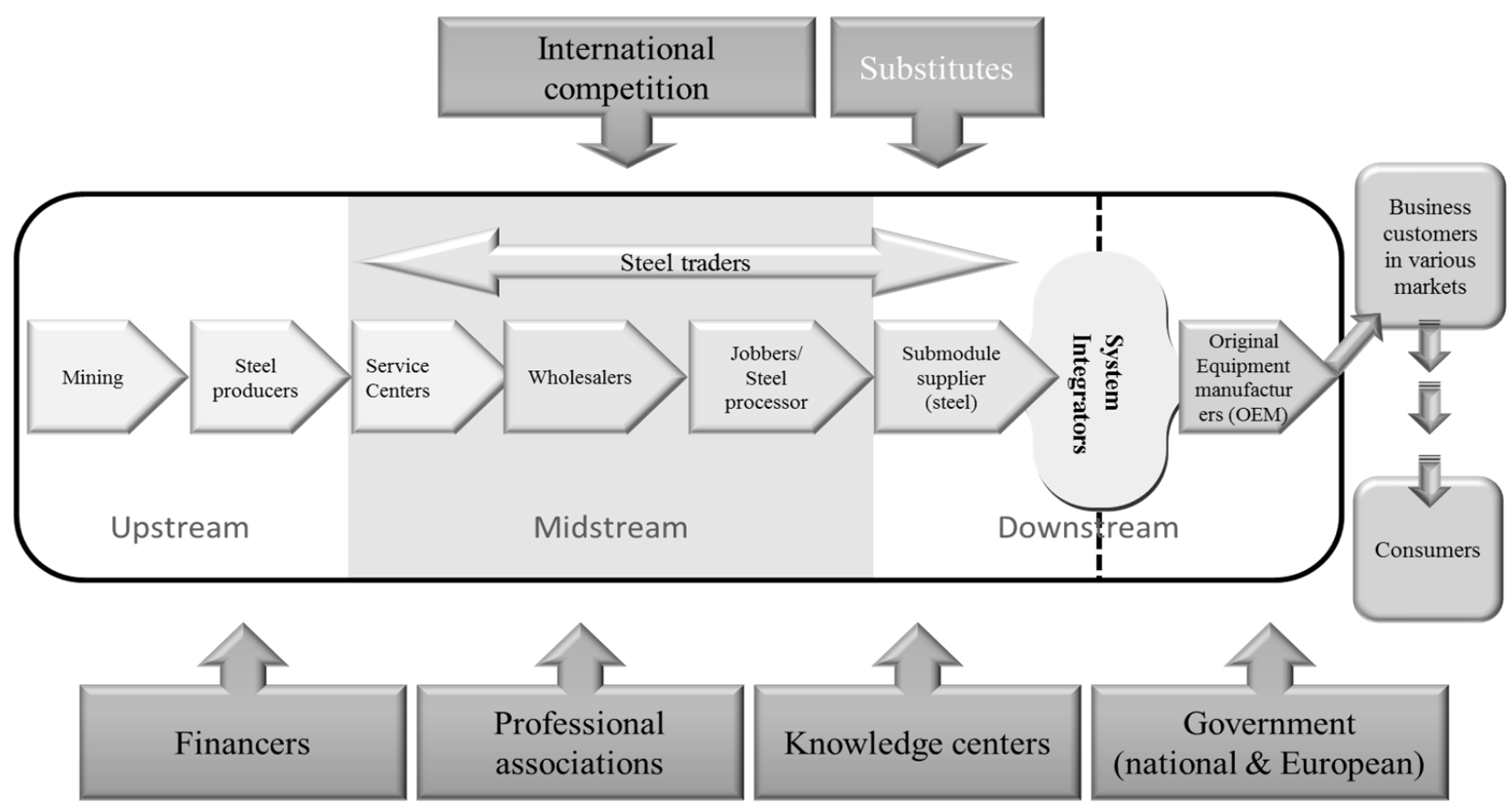

The case reported here, demanded for a collective effort to make the steel value chain more innovative, as the challenges to the industry led to a deinstitutionalization of its entire business model and thus a combination of higher-level functional, political and social challenges. First, there was a tangible erosion of functional role demarcations. Players in the midstream started combining multiple roles at once, e.g. distribution, primary cutting and coating, and several links in the long steel chain often got bypassed. On a social level, this lead to increasingly fragmented midstream markets and increased search behavior among players there that sought for some way to provide an answer to this new 'market-pull' model. On a political level, they had, however, lost the position to change their situation, as they had now become dependent on systems integrators. Even large European steel producers had little control over the chain anymore, as their price-setting position had become over-ruled by the heavily increased power of Asian players and iron ore miners.

The remainder of this section will focus on three networks that enabled such collective efforts to tackle the challenges threatening the competitive position of the steel industry as a whole. To this effect they were aimed to improve the sector's position in specific areas: 'Building with Steel' towards the steel construction market, 'Federation Metal Sheet' towards the manufacturing industry and the 'Society for Surface techniques of Materials' towards the specific issue of conservation affecting the steel chain's competitive position versus substitutes.

\section{2. 'BUILDING WITH STEEL'}

Created officially in 1961 as 'Steelbuilding Society', this federation was a continuation of a rich tradition of confederation activity in the Dutch steel and building industries. It actually took form within the research commission of the in 1954 erected 'Center Building in Steel' foundation, with the explicit intention to unite all institutions, enterprises, services and societies involved in steel construction. In the beginning, it mainly served as a gathering of engineers, academics and steel construction professionals to enable innovations throughout all aspects related to steel construction. This initially resulted mainly in the diffusion of steel construction innovations, such as a quicker building approach by assembling larger parts on site, imported from Paris, but a fair share of domestic-grown innovations as well. At that time, the Dutch steel construction industry was an international benchmark with the construction of the Delta works driving technological innovation and engineering excellence. Its leadership was hence under the supervision several leading engineering agencies and the society started in close collaboration with the technical university colleges of Delft and Eindhoven. 
By 2012, the 'Building With Steel' (BwS) federation counts over 2500 members, who actively participate in densely tied structures aimed to support the overarching goal of promoting the use of steel in the Dutch construction market (Figure 4). Its activities focus on specific areas such as knowledge sharing and retention, research and regulatory affairs. They can be related to the forward-looking compliance and competitiveness of steel construction applications, such as energy neutrality or smart flooring systems. Although the association is loosely coupled, its innovation projects originate through task-forces which tightly integrate the efforts of all relevant players in the supporting value chain for that specific innovation. These task forces also receive wide support from different types actors involved in the broad steel construction value chain, contractors, end-users, technical university-affiliated and other researchers and teachers, financiers and complementary service and product suppliers. This openness toward different stakeholder groups is also apparent in the federation's activities outward-facing activities, such as organizing special topics classes in Dutch universities and colleges, industry and student awards, trimestral open house \& networking events, or yearly seminars towards steel construction architects, contractors, engineers, designers, professors and construction supervisors.

Figure 4: Functional membership structure of the BwS network

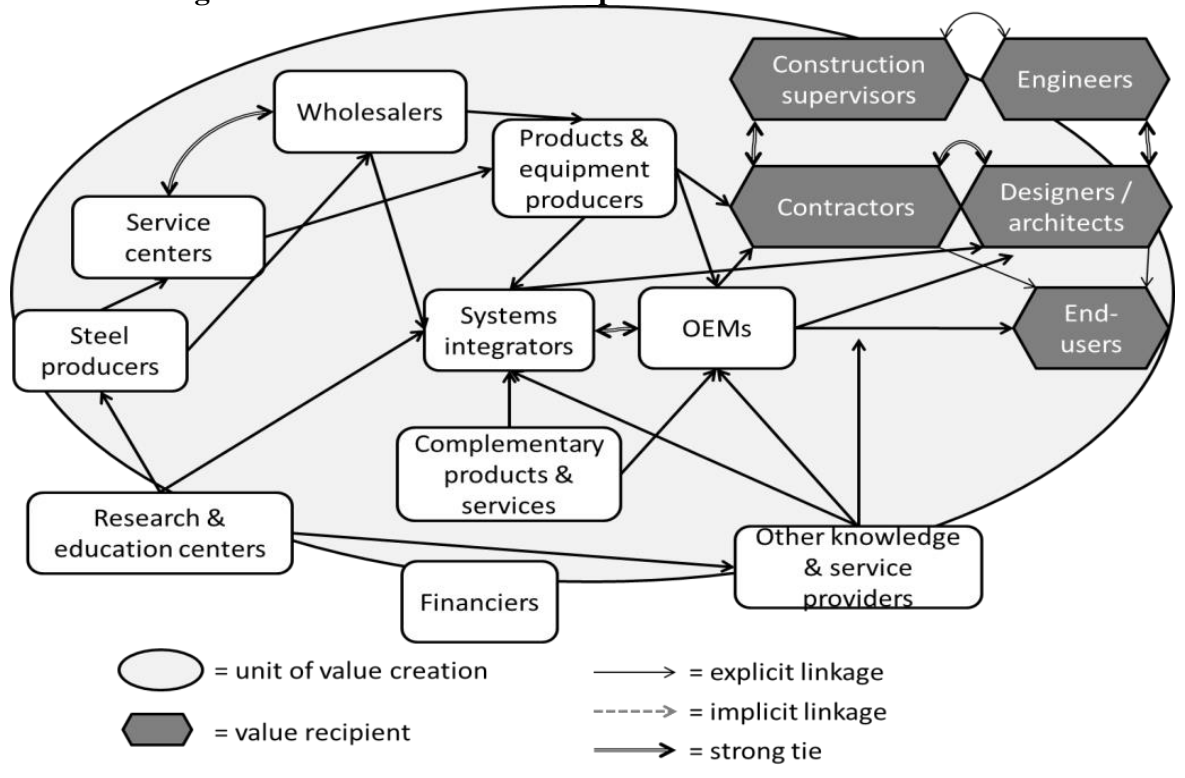

In its current form, $\mathrm{BwS}$ serves as a platform for multiple simultaneous innovation programs to develop entirely new customer value oriented total solutions. Most innovations are initiated and executed by one of the association's market-focused teams or one of its ten technical commissions. These technical commissions are focused on issues closely related to the general challenges faced by steel construction stakeholders, such as material durability, fire safety, joints, or construction stability or on specific productmarket issues, such as constructions for the utility market, bridges, or steel-concrete constructions. Under the direction of BwS's supervisory commission on research, regulations and standards, projects are also initiated aimed to support members' value activities in the long term. It supervises the relevance and coherence of decentralized research efforts in these various projects and sets its own annual longer-term research agendas. These projects can be oriented at developing industrial standards or in some other way on developing solutions for existing barriers to effective and efficient use of steel in construction projects, such as steel conservation, or the technicalities of remedying 'cold bridges' when using steel in building facades.

BwS has been rather successful in achieving its higher-level ambitions. It has successfully opened up the steel chain towards all relevant partners in the steel construction value chain and has involved them integrally in market-oriented innovation projects. Within its original market of suppliers to the construction industry, $\mathrm{BwS}$ estimates reaching more than $65 \%$ of relevant players, that is with more than 
two employees. Other stakeholders as well show a great deal of interest as the federation's projects, as they generally result in valuable outcomes for all parties involved.

\section{3. 'FEDERATION METAL SHEET'}

Federation Metal sheet (FMS) grew out of an experienced need for a body to stimulate dialogue and innovation in the entire steel chain and represent its interests towards the different end markets. It actually spawned from a gathering of the top management of Corus, a large steel producer, MCB, a large diversified wholesaler, Contour, a systems supplier and Ahrend, a large office furniture OEM in 1997. They started a dialogue discussing the future of the Dutch steel supply chain towards industrial sectors in the light of increasing delocalizations. All these parties had a genuine interest in knowledge sharing and development about materials and how they are to be processed, so that innovations could be diffused faster throughout the chain and the new technologies would thus be made available to OEMs faster. FMS currently counts 200 members, which are all closely related to the steel chain: OEMs, jobbers, wholesalers, service centers, steel producers and certain related knowledge providers, such as design and software agencies and technical universities and colleges. FMS's activities are explicitly aimed at strengthening the steel chain's competitive position internationally.

FMS's initiatives focus on metallurgic and process innovations. They seek to promote the use of metal products instead of substitutes in the manufacturing industry by presenting engineers or designers with factual data about the possibilities of different types of metals. This way, they want to stimulate new applications pushing the limits of the material ever further. According to the federation's president, "The FMS thereby does not aim to really position metals against plastics, a potential substitute", as both can often be combined for a better product. Yet, co-development with such potential complements for value innovations is not pursued within the federation, although it does exist in high value-added markets, such as aeronautics. The federation is furthermore active in larger-scale projects with universities and knowledge centers, which have as output a fact sheet with production process-relevant knowledge which is then disseminated to members.

Specific areas of action are the initiation of chain-wide technological research projects, promoting the steel industry and bridging the gap with steel-related educations. The FMS structure (Figure 5) and activities are specific to the steel chain and try to build on and reinforce the competencies in that chain, relating to current and future material knowledge, production techniques, and trends in the capacities of sheet metals. The federation allots less attention to the potential applications and related needs in endmarkets. In fact, its focus stops at the OEM-level. Both the network's structure and membership follow the traditional supply chain structure to a high degree. Although FMS is aimed at the broad goal of collectively promoting sheet metal as an industrial material, this goal is viewed from an OEM perspective and it does not explicitly integrate members not directly involved in the supply chain already. It resembles an interaction platform for one type of value recipients with the various parties creating that value.

Figure 5: Functional membership structure of the FMS network

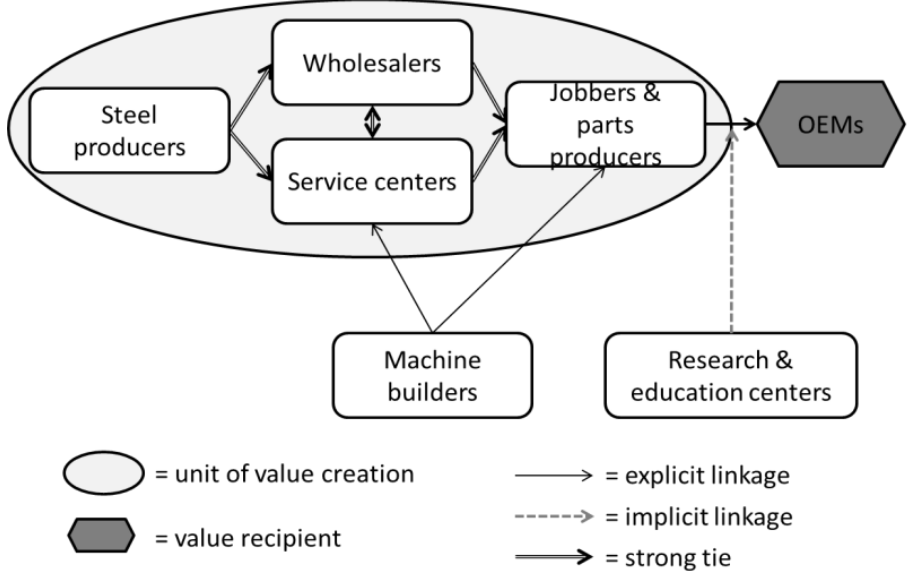

Page 13 of 32 
The federation considers its knowledge sharing goals to be well met within the industry on topics relevant for the production process, such as laser welding or high strength steel. However, we found that the knowledge shared between the chain partners is rather on a generic level of materials and basic production processes. Real innovation projects leading to a new offering or role towards the market incubated within the federation are scarce and hardly diffused, partly because they are entirely funded and carried by the members themselves.

FMS had the advantage of having OEMs, the intended recipient of the network's value creation, involved from the start. Nonetheless, knowledge sharing towards the industry's customers is, even according to the federation itself, still poorly established. In the long run, OEMs did not remain so interested in the improvement of the metal sheet value chain. Their engagement faded once a number of issues regarding the consistency of quality were being solved. In markets where metals have a low impact on the entire added value, the steel chain had often been down-tiered by putting systems integrators in charge of managing the supply chain. These were not reached by the FMS. In terms of market acceptance, the FMS estimates that it reaches 15 to $25 \%$ of its target population and reports increasing problems asking members for financial or knowledge contributions.

\subsection{SOCIETY FOR SURFACE TECHNIQUES OF MATERIALS}

The society for surface techniques of materials (SSTM) was founded to represent the interests of surface treatment firms in 1956. Although it is clearly a significant issue in the steel value chain, surface treatment was not organized as a category in the different existing steel chain associations. Besides uniting and representing players in the surface treatment segment, the society was especially oriented towards the stimulation of knowledge transfer, which led to the establishment of a dedicated 'advice center'. Even today, most of the SSTM activities are centered on education and knowledge sharing. The society's activities are furthermore aimed at standard-setting, certification, knowledge creation and lobbying. Despite its clear focus on a specific niche in the steel value chain, surface treatment had proven essential to the entire chain's competitive position, as steel conservation is a crucial issue in the competition against substitutes such as plastics or concrete.

The SSTM network is currently structured around different technology applications for metal conservation. It is organized in 2 levels (Figure 6). The central core of the network consists of organizations directly involved in the conservation of metal, such as galvanizers, anodizers, thermal galvanizers, wet and powder coaters. The network's activities strengthen the ties between these conservation specialists are furthermore organized in eight specific subnets, aimed at the further developments of these specialisms through knowledge sharing and standard setting. To also explicitly engage stakeholders interested in metal conservation, but not directly involved in the value creation process, the federation has opened its network with the aim of disseminating the platform's bundled transdisciplinary knowledge about metal conservation. Members in this outer layer of the network consist almost exclusively of the downstream contractors and project owners who have an intrinsic interest in the development of better applications. These members have been trickling in since the last 2 years and now account for approximately 5\%. They are highly interested in the network's technical expertise and the technological development projects. 
Figure 6: Functional membership structure of the SSTM network

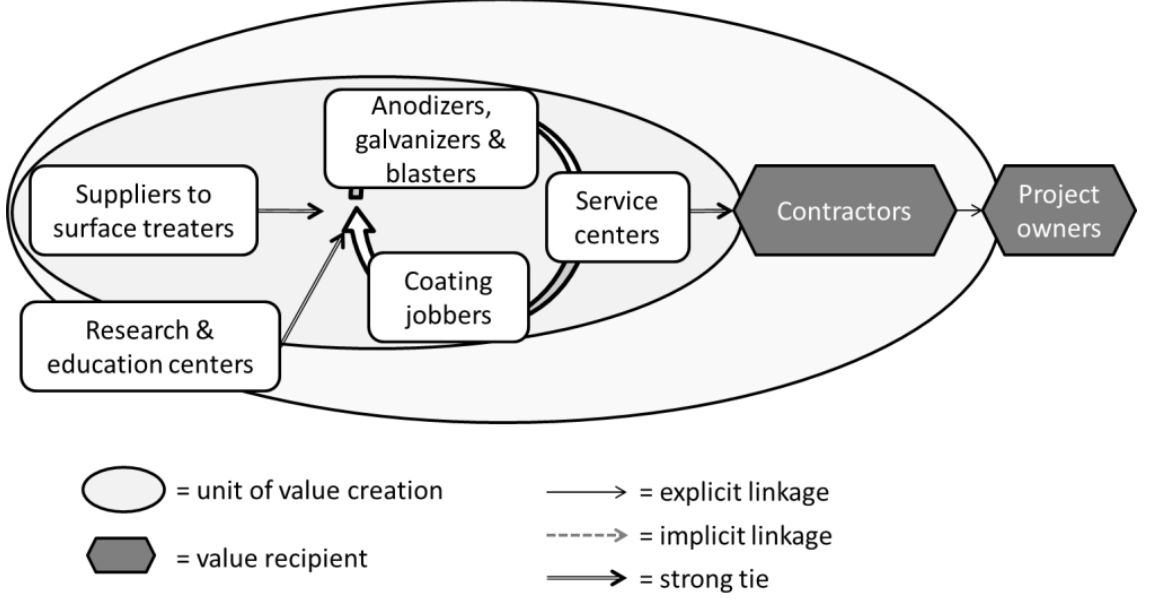

The educational activities of the SSTM are well-funded, well-attended, considered highly topical and numerous. To this end, research and education partners are strategically included in the network, as they "form the spine of our education programs and our innovation projects", dixit the society's president. Likewise, the SSTM seems to achieve its goal of improving exchange between members. The surface treatment industry actually consists of multiple clusters, each with their own specializations and technologies. Members are hence eager to learn from each other and to combine their respective technologies to create a more valuable offering (e.g. galvanizers working with partners for an additional colored finish).

With regard to representing the industry's interests, the SSTM currently dedicates a lot of attention to representing the segment's interests concerning the European Commission's 'Registration, Evaluation, Authorisation and Restriction of Chemical substances' regulation (REACH). Aimed to protect human and environmental wellbeing, the regulation affects most of the surface treatment firms as it eventually will imply banning hazardous chemicals and restricting their use only to certified firms. This implies a high degree of insecurity for these firms, as they are not certain whether they will obtain such a certificate and thus be able to continue their activities. In this case, the SSTM represents their interests by 'preregistering' substances that are vital to the activities of its members, so their registration is delayed for some more years, and by informing and preparing members for the certification process.

Besides the education and lobbying activities, the SSTM also accommodates the initiation and execution of collaborative innovation projects, which are mainly carried and funded by members. This appears to be somewhat successful with certain high-profile innovation projects that are diffused to the entire field albeit in moderate numbers. Recent innovation activities by the network have been affected by the post-crisis business climate, but the SSTM still maintains a separate budget and keeps initiating these projects. These are now marked by a higher sense of urgency and therefore more often aimed at direct commercialization rather than radical technological breakthroughs.

The society's success in terms of market acceptance is somewhat mixed, as its members represent $60-65 \%$ of the more technology intensive groups, such as galvanizers, glass bead blasters and the suppliers to the surface treatment segment, yet only $30-35 \%$ of powder- and wet coaters. A factor greatly benefiting the success in gaining market acceptance, however, is the network's connection with its target stakeholder. Although it focuses on a specific B2C problem, the SSTM still has a captive user base of mainly contractors, with even a willingness to pay for membership and the services offered by the network.

\section{CASE ANALYSIS}

As indicated in $\$ 4.1$, the actual setting to which we expose our literature-based analytical frame of IN institutional effectiveness, involves innovation that is situated in a domesticated market and hence triggers 
deinstitutionalization. The global character of the challenges facing the steel chain, as well as the distance with downstream players they needed to realign with, put the challenge for steel companies beyond the reach of single firms. Attempts to innovate failed because first they needed to improve the image of the entire chain, before downstream partners would consider them as co-creation partners. A strategic repositioning of the industry required devising new institutional arrangements. The case illustrates how this was enabled by organizing into 'network associations' that go beyond the vertical steel chain structure to address issues relevant to downstream players. This section reports the insights derived from this iterative confrontation of extant IN management frameworks with this specific context that precipitates institutional innovation. It explores what did and did not seem to work, which allows making suggestions about the institutional effectiveness of IN in the next section. First, we briefly discuss the reinstitutionalization practices these networks helped achieve and second, we examine how the configuration of the three network led to differences in their outcomes.

\subsection{EFFECTIVE REINSTITUTIONALIZATION PRACTICES}

\subsubsection{Alignment}

Due to the specific, industry-spanning nature of the challenges needing to be addressed, steel chain parties needed to revert to collective action. As a stable and limited circle of business contacts fed steel chain players' resistance to change, this first required them to look beyond their current, often opportunistic competition logics and to find ways to combine their forces, so as to make the industry as a whole relevant again in the eyes of its users. To furthermore also acquire downstream players' buy-in for this collective action, developing a shared vision with network partners, one that was consistent with their longer term interests, was vital. Whereas the solution frame was something that was co-constructed by partners in innovation networks, the diagnostic or problem frames needed to be relevant for the downstream parties from the start. A European industry federation market intelligence director claimed that parties in the steel chain "insufficiently know what their customer is doing and therefore lack the insight for innovation", almost literally acknowledged by a steel producer's marketing manager. In less successful projects, actors did not want to invest time in something they did not perceive as an important problem.

To achieve such alignment in two directions, network goals needed to be framed as an issue of interest to the network's value recipient(s) and it needed to be boundary-spanning so as to incorporate all the functions to address this issue. BwS, clearly the most successful network, therefore contained a highly diverse membership of not only steel chain parties and customers, but also architects, engineers, coating experts, installers and even software experts, education partners and governments. This would help them to overcome poor knowledge of steel construction possibilities among the architects and implementers as well as improving and demonstrating the sustainability of steel construction.

\subsubsection{Negotiations and making wise trades}

Pertaining to the negotiations for collaborative innovation, we found that success in this phase was entirely contingent on the ability to align frames. In the FSS, where this was not the case, negotiations were tough especially regarding the distribution of investments and intellectual property rights and they mostly prohibited broader diffusion of the innovation. Nonetheless negotiations were an indispensable part of all the open innovation projects to set project boundaries and allow a transparent discussion of the commercial and other applications afterwards. They were just secondary to the a priori congruence between the different partners' frames. Their success was evident from the fact that more innovative firms did cooperate "even though this meant they had to share their knowledge" with their peers, dixit one network president. This meant abandoning a focus on the direct gains from the project in exchange for expectations of future product leadership or just the possibility of creating offerings that are highly appreciated by the market and that offer prospects of doing good business.

Another aspect significantly influencing the achievement of the networks' reinstitutionalization goals is their ability to envision a bigger picture - and to suggest the need for an action capacity at a suited level. The development of the networks was fueled by recognizing drivers at broader economic and societal 
levels, such as substitution, sustainability - affecting steel intensity (meso level) - or demands placed on their customer - affecting total industry growth (macro). Essential for this bigger picture was the recognition of interdependencies in the industry's offering. One such interdependency was for instance the position of the recipients of these offerings. One general manager of a best practice integrated chain player phrased it as: "we hinge our success on our ability to help our customers win contracts... that's why we become their project managers and make it our responsibility to find the competences for a solution to their problem". The chain's offering was also interdependent with that of other - substitute or complementary - supply chains from the standpoint of the systems integrator combining them for endmarket applications (Figure 7). This realization opened up steel chain parties' contextual awareness and enabled the development of a meso-perspective to take action.

Figure 7: The system integrator's market-pull perspective on orchestrating multiple chains

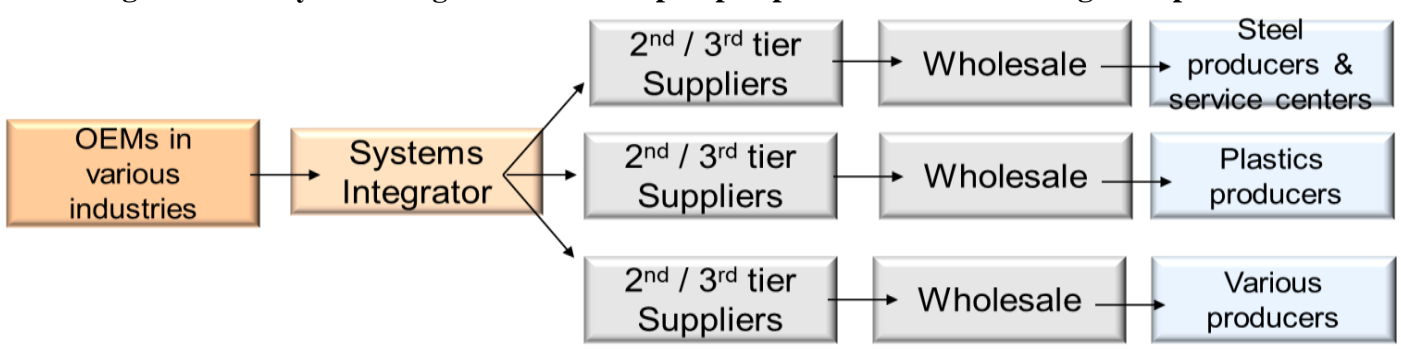

Successful initiatives under the umbrella of the network federations were able to turn these interdependencies into opportunities. A CEO of a large diversified steel distributor, for instance, claimed that "the chain has become a circle with cradle-2-cradle and for us it is now becoming a globe of interconnected network ties". This comment referred to successful projects within BwS uniting all players with an influence on the steel chain's environmental performance and associated with the recycling chain to measure and improve the eco-friendliness of the material. This was for instance an important issue for public infrastructure contracts. Involving all the players in such holistic projects also required securing some of the value created for them. In the past, steel chain players tended to look for opportunities locally, within their direct environment. Change initiatives were hence predominantly aimed at either their current customers or toward increasing their market share to the disadvantage of direct competitors.

\subsubsection{Respecifying roles}

Besides dealing all stakeholders in on the gains from innovation projects, institutional innovation also requires a new institutional template, a new value configuration for the industry that is better aligned with the demands posed on it. The search for such a new model was aided by the deinstitutionalization of existing roles in the old production-push model, which were becoming obsolete in the eyes of downstream players. So players, certainly in the midstream, began looking for new ways to create value for endmarkets. To respond to the deinstitutionalization challenges in a structural way, the steel chain opted for transversal network federations. These federations include partners from within the supply chain, as well as companies fulfilling complementary tasks in the value chain toward end markets, institutional and knowledge partners, and even lead users. This broader inclusion of relevant stakeholders coincided with role specification oriented at complementary capabilities and the potential added value that stakeholders could bring to the development of new value propositions. The extent to which and why these networks better fit the new context, is explored in the following section.

\subsection{THE INSTITUTIONAL EFFECTIVENESS OF NETWORK CONFIGURATIONS}

Although all three networks studied here had been around for much longer, they have become substantially more salient in the last decade. In this period, their membership and activities gained more attention by players in the industry as they are particularly seen as potential answers to the deinstitutionalization challenges facing the industry. Rather than the traditional 'industry federations' representing separate industry segments, these federations offered an open platform and coordinating mechanisms to help align diverse stakeholders in innovation projects and instigate collective action. Their 
field-level innovation goal makes them a special kind of IN, which we label institutional innovation networks (IIN). The remainder of this section develops the IIN concept and contrasts it to existing conceptions of IN. Moreover, there are noticeable differences in these IIN's effectiveness at achieving their long-term goals, both perceived by respondents and measured in terms of our conceptual model's supporting outcome factors. This allows the identification of success factors explaining their differential success in growing and diversifying both their membership and innovation activities. Based on our analysis of the three networks studied, following the analysis frame, Table 1 presents the eventual configurational characteristics of these IIN. Consistently iterating between the data and several theories resulted in a selection of factors that appeared to influence the performance of these networks. These factors were clustered in three categories: (i) the determination of the network's activities and the capabilities of the actors involved, (ii) the network's goal and (iii) its structure. 
Table 1: Analytical institutional IN configuration templates

\begin{tabular}{|c|c|c|c|c|}
\hline & \\
\hline & & BwS & FMS & SSTM \\
\hline \multirow{6}{*}{$\begin{array}{l}\text { Business net } \\
\text { type }\end{array}$} & Goal & $\begin{array}{l}\text { New business concepts \& product } \\
\text { development, knowledge creation \& sharing } \\
\text { focused on improving steel construction. } \\
\text { Broad meso-level goal }\end{array}$ & $\begin{array}{l}\text { Building a better metal sheet product and } \\
\text { improving the way it is handled throughout the } \\
\text { steel chain }\end{array}$ & $\begin{array}{l}\text { Interest promotion and technical } \\
\text { knowledge development of different } \\
\text { types of surface treatment players. } \\
\text { Highly specific meso-level goal }\end{array}$ \\
\hline & $\begin{array}{l}\text { Scope \& } \\
\text { determination }\end{array}$ & $\begin{array}{l}\text { End-market solution focus; wide diversity of } \\
\text { activities and technologies }\end{array}$ & $\begin{array}{l}\text { Knowledge acquisition, creation and } \\
\text { dissemination }\end{array}$ & $\begin{array}{l}\text { Niche application further divided into } \\
\text { subspecializations }\end{array}$ \\
\hline & & $\begin{array}{l}\text { Vertical, horizontal \& lateral grouped in task } \\
\text { forces }\end{array}$ & $\begin{array}{l}\text { Vertical, horizontal \& lateral - no functional roles } \\
\text { assigned }\end{array}$ & $\begin{array}{l}\text { Two-tier structure: surface treatment and } \\
\text { steel service centers in core; contractors } \\
\text { as separate 'user' tier }\end{array}$ \\
\hline & $\begin{array}{l}\text { Position } \\
\text { towards end- } \\
\text { user }\end{array}$ & $\begin{array}{l}\text { Explicit focus on end-user applications \& } \\
\text { involvement of downstream end-user service } \\
\text { providers' value chain. }\end{array}$ & $\begin{array}{l}\text { No end-users involved, aimed at creating input } \\
\text { for OEMs, which are also involved. }\end{array}$ & $\begin{array}{l}\text { Focus on niche application issue for } \\
\text { contractors, who are included in the } \\
\text { network and provided a central point of } \\
\text { information and contact. }\end{array}$ \\
\hline & Goal unity & $\begin{array}{l}\text { Shared market-focused goal in the interest of } \\
\text { most types of actors involved }\end{array}$ & $\begin{array}{l}\text { Compromise; direct interest of steel midstream, } \\
\text { other members with no stake in network results. }\end{array}$ & $\begin{array}{l}\text { Niche goal of direct interest to } 3 \text { types } \\
\text { of stakeholders involved. }\end{array}$ \\
\hline & $\begin{array}{l}\text { Planning } \\
\text { horizon }\end{array}$ & $\begin{array}{l}\text { Long-term strategy \& supporting short-term } \\
\text { projects }\end{array}$ & $\begin{array}{l}\text { Long-term finality \& related repository } \\
\text { accumulation }\end{array}$ & $\begin{array}{l}\text { Mostly shorter term projects within } \\
\text { scope of fixed long-term goal }\end{array}$ \\
\hline \multirow{3}{*}{$\begin{array}{l}\text { Actor } \\
\text { Heterogeneity }\end{array}$} & $\begin{array}{l}\text { Functional } \\
\text { complementa } \\
\text { rity }\end{array}$ & $\begin{array}{l}\text { High, issue-oriented competence \& role } \\
\text { complementarity; Bridging roles to overcome } \\
\text { knowledge gaps }\end{array}$ & $\begin{array}{l}\text { Non-redundant competences \& activities; supply } \\
\text { chain-like specialization }\end{array}$ & $\begin{array}{l}\text { High competences \& functional overlap, } \\
\text { but complementarity in technologies; } \\
\text { Knowledge centers in bridging role }\end{array}$ \\
\hline & $\begin{array}{l}\text { Cognitive- } \\
\text { cultural } \\
\text { heterogeneity }\end{array}$ & $\begin{array}{l}\text { Relatively high sector-based cognitive \& } \\
\text { cultural differences; complementarity in } \\
\text { network pictures }\end{array}$ & $\begin{array}{l}\text { Relatively low cultural heterogeneity; similar } \\
\text { network pictures limited to traditional chain }\end{array}$ & $\begin{array}{l}\text { Some cognitive-cultural difference } \\
\text { between more and less technologically } \\
\text { advanced segments }\end{array}$ \\
\hline & $\begin{array}{l}\text { Political - } \\
\text { normative } \\
\text { resource } \\
\text { endowment }\end{array}$ & $\begin{array}{l}\text { Substantial separate project budget } \\
2500 \text { members } \\
\text { Strong involvement of central actors in all } \\
\text { relevant stakeholder categories }\end{array}$ & $\begin{array}{l}\text { Limited budgets exclusively for conferences, no } \\
\text { project budgets. } \\
200 \text { members } \\
\text { Very limited activation of central players outside } \\
\text { traditional supply chain }\end{array}$ & $\begin{array}{l}\text { Budgets mostly for education, know- } \\
\text { ledge sharing and networking; projects } \\
\text { mainly funded by members } \\
350 \text { members } \\
\text { Intrinsic participation by third-party } \\
\text { research centers }\end{array}$ \\
\hline \multirow{2}{*}{$\begin{array}{l}\text { Organization } \\
\text { al strength }\end{array}$} & $\begin{array}{l}\text { Network } \\
\text { governance } \\
\text { model }\end{array}$ & $\begin{array}{l}\text { Decentralized \& coordinated by network } \\
\text { organization; matrix structure with market } \\
\text { oriented commissions \& transversal } \\
\text { supervisory commissions }\end{array}$ & $\begin{array}{l}\text { Participant-governed; decentral agenda-setting \& } \\
\text { project responsibility }\end{array}$ & $\begin{array}{l}\text { Agenda-setting by most central } \\
\text { members; projects co-funded by specific } \\
\text { members \& executed in task forces with } \\
\text { third parties }\end{array}$ \\
\hline & Tie strength & $\begin{array}{l}5 \text { annual meetings + seminars, workshops, } \\
\text { award events... } \\
\text { Lower emotional closeness between members; } \\
\text { intense association with specialized project } \\
\text { relationships \& goals }\end{array}$ & $\begin{array}{l}10 \text { meetings per year } \\
\text { Some emotional closeness between members } \\
\text { from supply chain relationships; moderate } \\
\text { association with higher-level goal }\end{array}$ & $\begin{array}{l}10 \text { meetings per year } \\
\text { Some emotional closeness between } \\
\text { members; high involvement with higher- } \\
\text { level and projects goals }\end{array}$ \\
\hline
\end{tabular}

Page $\mathbf{1 9}$ of $\mathbf{3 2}$ 


\subsubsection{Business net type}

Besides heterogeneity and organizational strength, we aimed to differentiate each IN based on its level of determination, and on its goals. There was substantial differentiation between the three networks in terms of determination, relating to their technological and functional content. At one end, BwS was a market application-focused network and therefore required a highly diverse constellation of technological capabilities. Accordingly, it contained a diverse set of actors with different specializations in e.g. engineering, design, architecture, materials science, construction and logistics. On the other end, the SSTM had a more narrow ambition explicitly targeting the technological possibilities and environmental issues concerning surface treatment. It therefore had a less broad, yet highly specialized competence base. Both networks thus appeared to possess 'requisite variety'. The mission of the FMS, however, appeared to be more ambiguous, which made it hard to specify which capabilities would be required to achieve it. A shortcoming perceived by players associated with the FMS was that it had always remained stuck in putting forward "the same high-level question" instead of really organizing towards specific answers.

With regard to the network's goal, we also take into account the planning horizon and goal unity or consensus. As mentioned above, the 'raison d'être' for these network federations consisted of their addressing of a higher-order finality that was beyond the scope of action for any firm or dyad. What seemed to differentiate successful networks was that their long-term goal was supported by specific shorter-term projects. In both BwS and the SSTM, these projects resulted in concrete points of action, rather than just an abstract mission. In terms of goal unity, these networks were furthermore successful because the higher-level issue addressed, was essential in the longer-term agenda of all participants. In contrast, in the FMS, the central issue was of interest to the traditional steel chain parties, yet other players such as the research and education partners or machine builders actually had little to gain by achieving its longer term goals. As such, the FMS also did not successfully engage in innovation projects before 2010 and its activities remain focusing on disseminating information within and creating awareness outside the steel chain. Its mission is not translated into concrete issue-based areas of collaboration.

\subsubsection{Actor heterogeneity}

Concerning heterogeneity, our literature review put forward mixed guidance, in that proximity was preferable in some dimensions and heterogeneity in others. Similarly, as we were analyzing heterogeneity, we found an important convergence of goals - vision proximity (Cantù, 2010) - in more successful networks. In the FMS, where such alignment of visions was lower, the diffusion of innovations was reportedly troublesome, as intellectual property concerns always prevailed and the non-central actors participated more as paid 'jobbers' than as intrinsic members. Technological proximity was important, as it enabled highly focused innovation projects that were relevant to the members of the SSTM. In BwS, however, the market-oriented network goal demanded an actor constellation with more diverse and complementary backgrounds. There, several types of designers, knowledge centers, engineers and other experts were involved in the various market-focused innovation projects. They functioned as development partners in the network to bridge existing technological gaps and to actually develop the ideas put forward in specific innovation projects. Such players also seemed to matter for the SSTM to bridge cognitive proximity gaps, as third party research centers were always included in the innovation projects to import the expertise necessary on e.g. the environmental properties of certain chemicals, which lay outside members' knowledge. According to its president, this contributed to the diffusing of these innovations as well.

Functional diversity was deemed necessary in both BwS and SSTM, as the previous paragraph indicates the need for a balance between having different sets of expertise within the task forces and on the other hand bridging potential gaps in knowledge to facilitate collaboration. In the SSTM, despite its narrow focus on a niche activity, complementarity was still sought in combining different sub-specializations. Differences in the cognitive-cultural dimension were not so much present in the FMS or SSTM. In the former, some respondents even suggested that the like-minded "club thinking" prevented the federation from noticing what was really relevant to potential strategic partners. It was seen as an important cause 
preventing the development of strategic action in areas where the federation could actually have an impact in promoting the chain towards end markets. A participant in BwS projects on the other hand considered it an enrichment that the various backgrounds of participants often challenged what task forces were trying to do, leading to "better, not just customer-oriented" innovations. The repeated success of BwS's innovation projects definitely contributed to its longer term ambitions. Such evidence was not found for heterogeneity in terms of power or centrality. In fact, the federation's president stressed the importance of having incumbents in all categories involved in its activities, to extend their reach and thus contribute to attaining its higher-level goal.

\subsubsection{Organizational strength}

Inspired by previous literature, we distinguish structural and governance determinants of organizational strength. With regard to the former, we noticed that tie strength when measured as frequency or duration, does not differentiate between successful and unsuccessful networks. Emotional closeness, a third classic measure of tie strength, has somewhat more equivocal implications. On the network as a whole and construed as a measure of dyadic tie strength with other members, respondents did not perceive much difference between the different networks. However, if considered as closeness to the overarching goal vision proximity - of the network, there seemed to be a relevant differentiation of intensity affecting its performance. This differentiation also seemed to be tied to network density, which is rather high in specific, temporary, issue-based innovation projects.

The more successful networks in terms of innovation output actively stimulated members practically selforganizing into task forces to address specific challenges. In the SSTM, these task forces usually consisted of multiple surface treatment specialists in combination with a third party research partner, to collectively tackle a specific technological or often also an environmental challenge. Consistent with BwS' broader, market oriented scope, task forces there had an even larger and more diverse actor composition, yet their stakes in the projects were rather high. These projects were seen as laying the basis for superior customer value and thus the future of these organizations. Even the research and education centers involved reaped benefits in the form of participation in long-term $R \& D$ programs with generalizable outcomes and an upgrade of the professions they supplied educations for. In contrast, the participant-governed structure of the FMS did not succeed in uniting members sufficiently to make an impact towards the higher-order goal.

\section{INTERPRETATION}

In the interpretation, we revisit the two parts of our research question. First, we look at the 'qualifying' elements separating IIN as a distinct type of network. We thereby focus on evidence of an explicit institutional entrepreneurship ambition. Second, we discuss 'success factors' that make such networks effective in reaching their institutional innovation goals. Accordingly, we draw inferences from our case examples in two ways. First, by abstracting the similarities across cases and comparing them to extant knowledge about regular IN, we triangulate qualifying characteristics differentiating between IN and IIN. Second, as the selected cases were ab initio known to have substantial differences in institutional effectiveness, we can also extract rudimentary propositions about the success factors for IIN to be validated in future research. In this section, the findings on both questions are also combined with the theoretical frames emerging in the second phase as most suited to explain them. This means that we link these findings to IN and social movement theory. From the latter, institutional entrepreneurship literature recurrently draws the actual micro-level 'framing' and 'resource mobilization' mechanisms constituting its process.

\subsection{WHAT MAKES IIN A DISTINCT CATEGORY OF IN?}

To answer this first question, we primarily look whether IIN indeed engage in reinstitutionalization practices, rather than just proclaiming to so. Given the limited body of knowledge available, the cases served as inspiration to discover which practices exactly characterize IIN. Furthermore, in answering this part of the research question, we also look at interdependencies between network configuration and the reinstitutionalization practices. Our initial conceptual model, inspired by institutional theory, construed 
IIN as networks with a goal addressing challenges at the organizational field level. As such, IIN are IN that come closer to resembling organizational field-nets (Kenis \& Knoke, 2002). Yet, in comparison they remain analytically distinct as they only include the explicitly mobilized members of that field who pursue the IIN's intentional innovation objectives, and who are thus actively engaged in collective institutional entrepreneurship. These networks thus better match the definition of a movement, a unit of collective action "outside of institutional channels" and with "change-oriented goals or claims; ... some degree of organization; and some degree of temporal continuity" (Snow et al., 2004, p.6). In this section, we compare our case findings to definitions of both IN and social movements. To further position IIN as a distinct concept combining characteristics of both, we extract three building blocks specific for IIN.

\subsubsection{Collective action mobilization}

A first commonality of our case networks, is their mobilization for collective action aiming to innovate the field. This typical social movement goal sets them apart from IN. Beyond bringing innovations to the market, IIN also aim to innovate that very market. The networks we observe, demonstrate configurational adaptations that seem tied to this difference. Certain taken-for-granted assumptions pertaining to IN's small-world structure, especially those of sparseness and asymmetry (Cowan \& Jonard, 2009), are loosened. In terms of asymmetry, the networks studied differ from typical IN characteristics in being more egalitarian. Typically, IN are marked by a visible degree of power asymmetry ${ }^{6}$, where one or a small number of hub firms steer the network, thereby imposing their interests more than less central members. Examples are the ecosystems around large software firms like Apple or Microsoft, which clearly focus on the product platforms of these central players.

The broader mission of IIN, however, seems to necessitate voluntary initiatives from member organizations. As such, their coordination is rather bottom-up and their membership more inclusive, also for direct competitors. They also tend to broaden their scope for action by attracting previously not activated parts of the organizational field and even including stakeholders outside the traditional predominantly technical or supply chain-oriented - definition of the field. As such, IIN are oriented and organized in a way that is different from IN and by which they come close to resemble social movements. What differentiates them from the latter, however, is that the central goal eventually has an economic rather than a social finality, which is more in line with IN.

Proposition 1: Institutional innovation networks that aim to enact field-level change are based on a member composition that (a) equalizes power asymmetries and that (b) complements intra-supply chain relationships with horizontal and boundary-bridging ties.

\subsubsection{Alignment, negotiation and wise trades via a 'network-administrative- organization'}

A second building block supporting the mobilization and goal achievement of IIN, seems to be their internal organization which is aimed at concentrating forces toward a common outcome. As the activities of the three networks are broken down into project-like team structures, there is a need for central coordination which balances bottom-up initiative with central oversight. As the projects support a higherlevel mission, the network presidents reported the importance of aligning them so they did contribute to those goals. Moreover, negotiation was also mentioned as an important issue in the innovation projects. Diffusing the findings from the projects required quite a balancing act from network administrators and members. To be encouraged to generalize their findings required the project teams to look beyond intellectual property hazards.

The observed networks did manage such alignment of project direction and conflicting interests by a neutral administrative organization body. This ties into an institutional conception of network governance. The network governance mode adopted is affected by the network's scope and complexity (Möller et al., 2005) and thus needs to be in line with its structure and the challenge it seeks to address. In increasing

${ }^{6}$ As opposed to more community-based structures, see Pisano and Verganti (2008) 
order of centralization, Provan and Kenis (2008) distinguish participant-governed, network administrative organization governed and lead-organization governed modes. Decentralized, participant-governed, networks are recommended in small networks with well-aligned players. In the context of IIN, however, this bottom-up emergent character is insufficient as tighter coupling through a network administrative organization becomes essential to collectively address higher-order challenges. Moreover, we also note that besides specific practices and the networks' governance mode, higher-level 'framing' of the network's goal turned out to be an important mechanism by itself. Although we considered this framing to be relevant mainly to the extent that it was matched with concrete practices to support the intended goal, it appeared to be effective in overcoming cognitive and normative innovation barriers.

Proposition 2: Institutional innovation networks balance member's commercial interest realization with wise trades for the common good through a central network administrative organization which combines neutrality and innovation roadmap alignment with central governance levers.

\subsubsection{Public good creation to enable innovation}

The difference of the studied networks with IN in terms of their sparseness seems to be related to a final building block, the creation of an innovation-enabling public good. Both the highly successful BwS and the moderately successful SSTM networks have highly dense cores of network members interacting intensely in value co-creation projects, collective lobbying and the creation of new business models and standards. Like social movements, IIN strive for a higher-level greater good. Like an IN, this greater good is in itself an innovation aimed at improved (economic) value creation. Besides innovating the field's business model, the resulting public good requires facilitating developments, externally and internally. These are also on a scale that necessitates collective action.

Externally, success of the institutional innovation is contingent on the extent to which the network is able to weigh on higher-level agendas. This requires being considered as a legitimate interest group and a frame that is picked up throughout the field (Benford \& Snow, 2000). Internally, effective reinstitutionalization necessitates a shared frame to emerge (Klandermans, 2004). To this end, framing seems to lay the path to achieving the three networks' mission to increase field-level innovativeness by changing the field's view on value creation. Much of the educational and conference activities of the networks were aimed at creating a shared awareness of new end-market needs and concerns. These socialization practices help transform frames by busting and replacing old myths about value throughout the field (Benford \& Snow, 2000). As their creation lies beyond the direct interest of private entrepreneur members, these enablers can be considered as a network-level commons.

Proposition 3: Institutional innovation networks' field-level public good creation rests on a mechanism of enabling network-level commons which provide access and status externally and adherence to a shared value logic as well as new competence levels internally.

\subsection{WHAT ARE SUCCESS FACTORS FOR IIN?}

This research question is answered by comparing performance-related differences between the three networks. The success factors differentiating between the low and the higher performing networks identified in the case analysis are systematically combined (Dubois \& Gadde, 2002) with social movement and IN principles. As the case-study only explored these networks' configurations and the way in which they supported the reinstitutionalization practices, these success factors are partial and in need of further validation. Nonetheless, they do provide a pattern that clearly separates IIN from other concepts like movements, IN or organizational field nets.

\subsubsection{Broad diagnostic frames for frame-bridging and frame-extension}

A crucial determinant of the higher-level impact of the three networks appeared to be the way the central goal was framed. Framing the common challenge gives meaning to the whole movement, so convergence on it crucially motivates collective action (King, 2008). To increase their frame's reach, institutional entrepreneurs strategically frame the issue in a way that attains substantial resonance among target stakeholders (Benford \& Snow, 2000). To do so, the frame needs to contain issues that are valuable or of 
interest to the specific actors they wish to target (Klandermans, 2004). Rather than through mobilization approaches adapted to each type of stakeholder, members were drawn to a network because its broader mission promised to address a salient common challenge. From a social movement perspective, this creates a shared identity and a sense of purpose, which increases the likelihood of collective action (Rowley \& Moldoveanu, 2003).

Institutional entrepreneurship spawns in strong contexts (Markman, 2007), which offer a clear direction of the barriers to be addressed. In the case of institutional entrepreneurship, this collective action more specifically addresses cognitive, normative and regulative barriers (Scott, 2008). From our case networks, we induce that this contextual strength is not a given tied to the challenge itself, but rather intentionally constructed. Although the root causes for the three networks' collective action were shared, they framed it differently, which led to differing success in attracting support. The FMS framed the problem more tightly, on a level that only triggered intrinsic motivation from steel chain parties. The two other networks centered around a frame that was framed in a more broad, strategic manner which enabled the mobilization of a broader set of stakeholders. It was oriented at the end-market, which eventually determines value for all actors in the value chain. Therefore, much like technological IN, the more clearly the network's common goal connects with end-market needs, the likelier its innovations will be successful. This illustrates the frame bridging and frame extending roles (Benford \& Snow, 2000) of these networks as key success factors for their market acceptance and innovation success.

Proposition 4: When diagnostic framing is based on a broad outcome that aligns with the interests of various stakeholders both on the demand and the production side, it has the tendency to increase mobilization effectiveness.

\subsubsection{Specific, co-creative and actionable prognostic frames}

What is also clearly different for the two more successful networks, is their ability to translate the problem framing into approaches that stimulate action. The prognostic frame is the "articulation of a proposed solution to the problem, or at least a plan of attack" (Benford \& Snow, 2000, p.616). It thus specifies milestones and roles which further align stakeholders with a shared goal and critically motivate them into action (Klandermans, 2004). These milestones and roles empower participants by channeling interest-led ambitions into a proper 'roadmap'.

However, even in the successful networks, there was considerably more disagreement about the appropriate solutions than there was about the diagnostic frame. Stakeholders from different industries, with different positioning strategies or roles in the steel value chain had different opinions on how specific parts of the collective challenge ought to be addressed. This led to a perceived tension within the network's management on how to reconcile these different opinions, without making the solution inoperable. The more successful networks have the ability to translate this heterogeneity into specific and shorter term project goals which triggered targeted collective action. As such, we observe that the approach to this inherently institutional ambition was met by organizing into multiple sub-IN, each oriented at a specific, actionable project. As such, broad goal framing was best accompanied by goal multiplexity (Oliver, 1988), not fuzziness.

Proposition 5: When the network's prognostic framing strikes a balance between embracing different norms or cognitions and practicability by dividing into specific projects, it supports role specification and has the tendency to increase institutional effectiveness.

\subsubsection{Completeness for political and innovative action capacity}

In industrial markets, where networks are highly salient to innovation process and strategy (Håkansson \& Snehota, 1990), we find strong indications that the IIN's capability to internalize value chain interdependencies determines its innovation strategy's success. Much in line with traditional IN findings, the development of complex solutions requires integration of all relevant links of the value chain towards the end-customer (Dhanaraj \& Parkhe, 2006). Moreover, from the reactions of network members, this value chain 'completeness' also appeared to be an important attraction factor for a diverse set of 
stakeholders. The likelihood that stakeholders would put their shoulders under achieving a common good is driven by the strength of a 'collective incentive', a factor of the salient value of the common good and the expectation it will be reached (Klandermans, 2004). The more a network was able to include all the necessary parts to develop an end-market solution, the more stakeholders were convinced of its action capacity to address the common challenges. Hence, value chain 'completeness' served an IN purpose by increasing innovative action capacity, as well as a social movement purpose by motivating participation and action.

Proposition 6a: Value chain completeness increases the likelihood of technically solving the common challenge and thus strengthens the collective incentive that attracts followers to the institutional innovation network.

Furthermore, like a movement, the institutional goals also require a normative-political action capacity (Greenwood \& Hinings, 1996). This action capacity is to some degree even mentioned in IN literature with tie strength (Freel \& De Jong, 2009) and network volume (Dhanaraj \& Parkhe, 2006) as structural performance determinants. Part of the assumptions of IN, however, two other determinants of structural action capacity are explicitly considered to be low. Organizational strength, which is instrumental to a movement's capacity to weigh on higher-level issues (King, 2008; Rowley \& Moldoveanu, 2003) entails (1) density for tight coupling within a network and (2) a critical mass. Unlike in technological IN, this mass necessitates including firms which compete for the same resources. While complicating the integration of different firms, this augments their capacity to bargain and tackle industry-spanning challenges. A further addition unique for these movement-like networks, is that their effectiveness, besides sheer mass and density, also depends on mobilizing influential mediating actors (Ritvala \& Salmi, 2010). As framing attracts counterframing by outsiders, success depends on the support by central players (Hinings et al., 2004). These are crucial in legitimating a movement, diffusing its goals and values and persuading others to join or condone.

Proposition 6b: A network's institutional effectiveness necessitates political-normative capital, consisting of density, a critical mass within stakeholder groups and the mobilization of critical mediating actors.

\subsubsection{Requisite variety in exploration and exploitation}

The ability to simultaneously explore and exploit is a third key success factor for IINs. In the pursuit of technological challenges, where there are clear technological innovation needs, yet no need for new organizing templates, the typical IN calls for a moderate distance between participants, especially in terms of competences (Cowan \& Jonard, 2009). Such a design leverages competence complementarity for value creation and reduces competence redundancy for optimal value capturing. Our networks adopt the IN organizing principles of self-organizing initiative and heterogeneity in terms of competence complementarity to improve exploration. The exploitation of the network is, however, disturbed when it contains competitive relationships which drive self-interest, rather than cooperation.

When there is also a high need for institutional development (Ritti \& Silver, 1986), like in domesticated markets, the network additionally requires central oversight. The three case networks resort to a "network administrative organization' (Provan \& Kenis, 2008), a formal organizing structure, which increases the likelihood and impact of collective action (King, 2008). In the least successful FMS network, this central body was present, yet it lacked organizational strength to assure the necessary coordination. This does not imply that the other two networks were governed in a centralized way, but they did contain certain agenda-setting, budgetary and project structure levers to coordinate member initiatives. However, as these structures derive from the allowances granted by members, they depend on the extent to which the central goal framing convinces members of the benefits of relinquishing autonomy to the central administration.

Successful IIN thus encompass structures to facilitate the simultaneous cooperative and competitive dynamics in structurally embedded networks (Gnyawali \& Madhavan, 2001). As such, the case seems to support both a strong ties argument favoring proximity for network exploitation and a weak ties argument, which expects diversity to improve a network's exploratory innovation capacity (Granovetter, 1973). We 
furthermore infer from the case networks that this balance is dynamic, driven by a mechanism of requisite variety. This helps explain why both SSTM and BwS could be successful relative to the breadth of their respective goals with substantially different configurations. The former suggests that smaller focused networks with a relatively larger technological proximity can be successful if the challenge is framed in a more specialized way that focuses on specific types of technologies or applications. The latter indicates larger size and more heterogeneous compositions as success factors if the goal is framed in a more broad and multiplex way (Oliver, 1988). These networks support the recombination of capabilities for breakthrough innovations by building on a broad competence base and development partners acting as brokers to bridge competence gaps.

Proposition 7: Alignment of exploration mechanisms like member diversity and self-organization to complete project value chains and of exploitation mechanisms like density and central project coordination for univocal, integrated field-level agency with the time horizon and the downstream reach of the network's goals tends to increase institutional effectiveness.

\section{CONCLUSION}

\subsection{THEORETICAL IMPLICATIONS}

The IN literature extends strategy models to incorporate ways to pursue collaborative advantage (Huxham $\&$ MacDonald, 1992) by tackling issues beyond the means of any single firm. By this, it implicitly focuses on a void in existing strategy literature regarding the intentional development of collaborative networks. The primary contribution of this study is that it ontologically expands IN literature beyond high-tech contexts of complex product development. It thereby extends IN literature by not only further reinforcing its contribution to the organization of open innovation, but by expanding the reach of purposes and contexts open innovation can be applied to as well. Whereas IN greatly contributes to the creation of innovative end customer value, we argue that IN can serve more ambitious purposes as well. This study explores how they can aid the strategic renewal of an institutionalized business field. Applying IN to domesticated contexts, which tend to oppress open innovation, it introduces the IIN concept as a template for institutional innovation through intentional collective action. These IIN act out of a necessity to address institutional challenges at the field level, on top of the market-oriented finality of IN. They open the black box of how cooperation at a meso network-level can be employed to intentionally redesign the overarching field. Although organizational networks can have a profound influence on their industrial and societal environment, the effective fulfillment of this institutional role, is relatively unexplored. Hence, a vast area for further development of these cross-level dynamics in IN literature remains to be uncovered. This paper makes a first attempt in unpacking the mechanisms through which networks can impact their field's performance.

This institutional entrepreneurship aspect appears to suggest that the IIN concept imports social movement principles to the study of IN. These principles and the explicit higher order goal distinguish IIN as a separate category of innovation-oriented networks. Our findings indicate that the success factors for IIN are often congruent, but not always identical to typical IN characteristics as they need to support specific reinstitutionalization practices. The areas in which IN and IIN do not overlap seem to be in line with social movement principles. For instance, the performance imperative for IN to stimulate actor proximity in certain dimensions (Cantù, 2010) and heterogeneity in others (Corsaro et al., 2012a) also applies to IIN. Proximity seems especially relevant between participants' end-user value frames. Heterogeneity concerning functional complementarity still facilitates these networks' value creation, yet more vital to their effectiveness seems to be their need for critical mass. As such, they comprise multiple competitive relationships of the same type, rather than limited participants and a lower competency overlap which is more typical in IN.

A second contribution of the paper is oriented at institutional entrepreneurship literature. By introducing IIN, we present a more agency-specific locus for institutional action than the broad concept of organizational field-nets, yet which does not suffer from the level ambiguity of institutional entrepreneurs, 
which are defined both as individual and collective units (Battilana et al., 2009). This paper conceptualizes the mobilizing and framing described in institutional entrepreneurship literature (Ritvala \& Salmi, 2010) as actually occurring at the level of a 'movement', a multi-actor network (Benford \& Snow, 2000). IIN can be seen as such movements, yet like IN with a goal aimed primarily at the market rather than the social arena. As a movement, they are a special kind of IN aimed to innovate institutional arrangements, rather than products. What is interesting, is that the movement characteristics of IIN lead to subtle violations of the small-world assumptions of IN, although both have been related in literature. So whereas we initially expected IIN to be a subset of INthey actually seem to be a distinct category. These IIN add to social movements a market-oriented embedded organization perspective (Gnyawali \& Madhavan, 2001). This results in a clearer conception of what's in, (the relevant parts of the value chain) and what's out (the external pressures from substitute value chains) and enables institutional strategizing from a business actor perspective.

Finally, the embedded design of the case-study also offers conclusions at the field level. The paper supports arguments in favor of innovation policies that focus on intentionally governed networks or clusters of organizations as platforms for innovation and public good creation (see e.g. Greenwood et al., 2002). It suggests that their actions should furthermore be focused on end-market issues and their output ought to be innovative public goods, such as an awareness and culture of innovation and structures that promote their realization, rather than innovations themselves. This helps them overcome negotiation stalls and moral hazard that could otherwise arise if the policy were to stimulate specific technological innovations rather than the cultivation of a more innovative system as a whole. IIN as such can be especially relevant to unblock domesticated markets, which makes IN literature relevant to public policy theorizing about innovation as well. As governments cannot instigate the bottom-up development of innovation networks or clusters, their involvement and support of IIN can be an intermediate vehicle to stimulate such innovative activity.

\subsection{INSTITUTIONAL INNOVATION NETWORKS: IMPLICATIONS FOR PRACTICE}

This paper offers a framework to guide managers engaging in the development of a network to strategically innovate their business field. In the face of deinstitutionalization of this field as a whole, firms can either opt to exit that field and look for sweet spots in related business fields that are less sensitive to these pressures. Or they can take the hard way and together attempt to substitute the obsolete business model of their industry with one that better fits the needs of the market. Frameworks for such ambitions are relevant alongside existing strategy and IN models as they present managers with entirely different challenges. Rather than assuming that IN emerge out of pure technical or economic necessity, intentional network development involves more than finding partners with complementary activities and resources. It implies that partners are not automatically attracted by prospects of direct financial benefits, but are rather mobilized through somewhat abstract higher-order goals (Ritvala \& Salmi, 2010). Mobilization thus becomes a more challenging and hence a relatively "central" task, requiring managers to pay explicit attention to the social-structural, institutional, aspects of network development. It warrants reassessing actors' functional role requirements within a larger value-creating system, regaining social consensus, realigning with political distributions and rethinking the links with stakeholders and the larger societal level (Oliver, 1992).

In our current and previous work, network development seems especially relevant in cases where it serves to innovate the business field, rather than the product or service offerings. When deinstitutionalization, rather than the search for new products or platforms triggers the development of an innovation network, it involves addressing a higher-level challenge. In this context, managers need to identify specific drivers of deinstitutionalization and then the appropriate levers to address them, so that a new, fitting model of value creation can be co-created. As suggested by Veal and Mouzas (2010), collaborative innovation requires managers to boast a multilevel orientation and to converge frames. It requires an ability to see the broader picture and make 'wise trades', to mobilize actors and to coordinate the value system for sustained engagement (Möller \& Svahn, 2009). Our study illustrates the need for an institutional fit of the network 
configuration with the full extent of the challenges faced and proposes a multidimensional framework to evaluate this fit. Managers involved in the creation of IIN might use these dimensions for guidance on trade-offs in their design. Furthermore, IIN' focus on membership volume and centrality instead of pure functional complementarity, will increase the number of direct competitors within a given network. An important challenge for managers lies in recognizing the added benefits of focusing on enlarging the pie for the entire field, instead of focusing on value capturing.

\subsection{FURTHER RESEARCH AND LIMITATIONS}

The findings of this study contribute to and aim to stimulate further research on the issue of network development, especially in the context of IIN. Due to increasing globalization, interconnectedness and stakeholder vocality, business fields will ever more be confronted with challenges that disrupt their existing arrangements and that require collaborative action. At this point, however, the guidance offered in literature is limited, leaving a vast and relevant opportunity for further theory building. Our findings suggest that such research should break away from traditional strategy models and that paradigms facilitating collective agency might likely offer fitting explanations. Just like innovation networks should entail a level of complexity and heterogeneity that is in line with the demands they seek to address, so should the theories and methods to explain them.

The interdependencies inherent in network strategizing warrant more research that is based on configurational conceptions of networks (e.g. Möller et al., 2005) or the required competencies and orientations (Hakala \& Kohtamäki, 2011), multidimensional conceptions of organizational distance (Cantù, 2010; Corsaro et al., 2012a), or that accommodates the multiple interaction effects between actors, resources and activities in networks (Ritter, 2000; Håkansson \& Ford, 2002). As such, we see a natural home for this stream of literature in the industrial networks approach, especially with its tradition of paradigmatic diversity. As this study is limited by the exploratory nature of the field, its main stride is to offer directions and some further support for researchers venturing into the field. Further research should validate and extend these findings by identifying further mechanisms, limits and conditionalities to the currently identified mechanisms through larger $\mathrm{N}$ studies with e.g. quasi-experimental, qualitative comparative analysis or quantitative designs. We furthermore argue that the concerns of external validity related to the single embedded case design are not problematic, as the mechanisms we abstract, apply generally to the context of domesticated markets. As these mechanisms explain network determinants of institutional innovation effectiveness, they can be useful even broader to any context requiring institutional development (Ritti \& Silver, 1986).

\section{BIBLIOGRAPHY}

Akerlof, G.A. \& Yellen, J.L., 1985. Unemployment through the filter of memory. Quarterly Journal of Economics, 100, pp.747-73.

Arndt, J., 1979. Toward a concept of domesticated markets. Journal of Marketing, 43(4), pp.63-75.

Astley, W.G. \& Van de Ven, A.H., 1983. Central Perspectives and Debates in Organization Theory. Administrative Science Quarterly, 28(2), pp.245-73.

Battilana, J., Leca, B. \& Boxenbaum, E., 2009. How Actors Change Institutions: Towards a Theory of Institutional Entrepreneurship. Academy of Management Annals, 3(1), pp.65-107.

Baum, J.A.C., Shipilov, A.V. \& Rowley, T.J., 2003. Where do small worlds come from? Industrial and Corporate Change, 12(4), pp.697-725.

Beer, M., Voelpel, S.C., Leibold, M. \& Tekie, E.B., 2005. Strategic Management as Organizational Learning: Developing Fit and Alignment through a Disciplined Process. Long Range Planning, 38, pp.445-65.

Benford, R.D. \& Snow, D.A., 2000. Framing Processes and Social Movements: An Overview and Assessment. Annual Review of Sociology, 26, pp.611-39.

Bianchi, M. et al., 2011. Organisational modes for Open Innovation in the bio-pharmaceutical industry: An exploratory analysis. Technovation, 31, pp.22-33.

Calia, R.C., Guerrini, F.M. \& Moura, G.L., 2007. Innovation networks: From technological development to business model reconfiguration. Technovation, 27, pp.426-32.

Cantù, C., 2010. Exploring the role of spatial relationships to transform knowledge in a business idea - Beyond a geographic proximity. Industrial Marketing Management, 39, pp.887-97. 
Cantwell, J., Dunning, J.H. \& Lundan, S.M., 2010. An evolutionary approach to understanding international business activity: The co-evolution of MNEs and the institutional environment. Journal of International Business Studies, 41, pp.567-86.

Chesbrough, H., 2003. The era of open innovation. MIT Sloan Management Review, 44(3), pp.35-42.

Corsaro, D., Cantù, C. \& Tunisini, A., 2012a. Actors' Heterogeneity in Innovation Networks. Industrial Marketing Management, 41(5), pp.780-89.

Corsaro, D., Ramos, C., Henneberg, S.C. \& Naudé, P., 2012b. The impact of network configurations on value constellations in business markets - The case of an innovation network. Industrial Marketing Management, 41, pp.54-67.

Corsaro, D. \& Snehota, I., 2011. Alignment and Misalignment in Business Relationships. Industrial Marketing Management, 40, pp.1042-54.

Cowan, R. \& Jonard, N., 2009. Knowledge Portfolios and the Organization of Innovation Networks. Academy of Management Review, 34(2), pp.320-42.

Cowan, R., Jonard, N. \& Zimmerman, J.-B., 2007. Bilateral Collaboration and the Emergence of Innovation Networks. Management Sicence, 53(7), pp.1051-67.

De Jong, J.P.J. \& Freel, M., 2010. Absorptive capacity and the reach of collaboration in high technology small firms. Research Policy, 39, pp.47-54.

Dhanaraj, C. \& Parkhe, A., 2006. Orchestrating Innovation Networks. Academy of Management Review, 31(3), pp.659-69.

Dimaggio, P., 1988. Interest and agency in institutional theory. In L. Zucker, ed. Institutional patterns and culture. Cambridge, MA: Ballinger Publishing Company. pp.3-22.

Dittrich, K. \& Duysters, G., 2007. Networking as a Means to Strategy Change: The Case of Open Innovation in Mobile Telephony. Journal of Product Innovation Management, 24, pp.510-21.

Dubois, A. \& Gadde, L.E., 2002. Systematic combining: an abductive approach to case research. Journal of Business Research, 55, pp.553-60.

Easton, G., 2000. Case Research as a Methodology for Industrial Networks: A Realist Apologia. In S. Ackroyd \& S. Fleetwood, eds. Realist Perspectives on Management and Organisations. London: Routledge. pp.205-519.

Easton, G. \& Araujo, L., 1994. Market Exchange, Social Structures and Time. European Journal of Marketing, 28(3), pp.72-84.

Enkel, E., Bell, J. \& Hogenkamp, H., 2011. Open Innovation Maturity Framework. International Journal of Innovation Management, 15(6), pp.1161-89.

Fern, E., 2001. Advanced Focus Group Research. Thousand Oaks, CA: Sage Publications Ltd.

Freel, M. \& De Jong, J.P.J., 2009. Market novelty, competence-seeking and innovation networking. Technovation, 29, pp.873-84.

Gemünden, H., Ritter, T. \& Heydebreck, P., 1996. Network configuration and innovation success: An empirical analysis in the German high-tech industries. International Journal of Research in Marketing, 13(5), pp.449-62.

Gilsing, V. \& Nooteboom, B., 2005. Density and strength of ties in innovation networks: an analysis of multimedia and biotechnology. European Management Review, 2(3), pp.179-97.

Gnyawali, D.R. \& Madhavan, R., 2001. Cooperative Networks and Competitive Dynamics: A Structural Embeddedness Perspective. Academy of Management Review, 26(3), pp.431-45.

Goerzen, A. \& Beamish, P.W., 2005. The effect of alliance network diversity on multinational enterprise performance. Strategic Management Journal, 26, pp.333-54.

Granovetter, M.S., 1973. The Strength of Weak Ties. American Journal of Sociology, 78(6), pp.1360-80.

Greenwood, R. \& Hinings, C.R., 1996. Understanding radical organizational change: Bringing together the old and the new institutionalism. Academy of Management Review, 21(4), pp.1022-54.

Hakala, H. \& Kohtamäki, M., 2011. Configurations of entrepreneurial-customer-and technology orientation: Differences in learning and performance of software companies. International Journal of Entrepreneurial Behaviour \& Research, 17(1), pp.64-81.

Håkansson, H. \& Ford, D., 2002. How should companies interact in business networks? Journal of Business Research, 55(7), pp.133-39.

Håkansson, H. \& Snehota, I., 1990. No business is an island: the network concepts of business strategy. Scandinavian Journal of Management, 4(3), pp.187-200.

Hargrave, T.J. \& Van de Ven, A.H., 2006. A Collective Action Model of Institutional Innovation. Academy of Management Review, 33(4), pp.864-88. 
Harrisson, D. \& Easton, G., 2004. Temporally embedded case comparison in industrial marketing research. In Fleetwood, S. \& Ackroyd, S. Critical Realist Applications In Organisation And Management Studies. Routledge. pp.194-233.

Henneberg, S.C., Mouzas, S. \& Naudé, P., 2006. Network pictures: concepts and representations. European Journal of Marketing, 40, pp.408-29.

Hinings, C.R., Greenwood, R., Reay, T. \& Suddaby, R., 2004. Dynamics of Change in Organizational Fields. In M.S. Poole \& A.H. van de Ven, eds. Handbook of Organizational Change and Innovation. New York: Oxford University Press. pp.304-23.

Huxham, C. \& MacDonald, D., 1992. Introducing Collaborative Advantage: Achieving Inter-organizational Effectiveness through Meta-strategy. Management Decision, 30(3), pp.50-56.

Kenis, P. \& Knoke, D., 2002. How Organizational Field Networks Shape Interorganizational Tie-Formation Rates. Academy of Management Review, 27(2), pp.275-93.

King, B., 2008. A Social Movement perspective of Stakeholder Collective Action and Influence. Business \& Society, 47(1), pp.21-49.

Klandermans, B., 2004. The Demand and Supply of Participation: Social-Psychological Correlates of Participation in Social Movements. In Snow, D.A., Soule, S.A. \& Kriesi, H. The Blackwell Companion to Social Movements. Oxford: Blackwell Publishing. pp.360-79.

Lawrence, T.B., Hardy, C. \& Phillips, N., 2002. Institutional Effects of Interorganizational Collaboration: The Emergence of Proto-Institutions. Academy of Management Journal, 45(1), pp.281-90.

Levin, D.Z. \& Cross, R., 2004. The strength of weak ties you can trust: The mediating role of trust in effective knowledge transfer. Management Science, 50(11), pp.1477-90.

Markman, G.D., 2007. Entrepreneurs' competencies. In J.R. Baum, M. Frese \& R.A. Baron, eds. The psychology of entrepreneurship. Ahwah, NJ: Lawrence Erlbaum. pp.67-92.

Matthyssens, P. \& Vandenbempt, K., 2003. Cognition-in-context: reorienting research in business market strategy. Journal of Business and Industrial Marketing, 18, pp.595-606.

Matthyssens, P., Vandenbempt, K. \& Weyns, S., 2009. Transitioning and co-evolving to upgrade value offerings: A competence-based marketing view. Industrial Marketing Management, pp.504-12.

Möller, K.K., Rajala, A. \& Svahn, S., 2005. Strategic business nets-their type and management. Journal of Business Research, 58, pp.1274-84.

Möller, K. \& Svahn, S., 2009. How to influence the birth of new business fields - Network perspective. Industrial Marketing Management, 38, pp.450-58.

Morgan, D.L. \& Krueger, R.A., eds., 1998. The Focus Group Kit. 16th ed. Thousand Oaks, CA: Sage.

Oliver, C., 1988. The Collective Strategy Framework: An Application to Competing Predictions of Isomorphism. Administrative Science Quarterly, 33(4), pp.543-61.

Oliver, C., 1992. The Antecedents of Deinstitutionalization. Organization Studies, 13(4), pp.563-88.

Pisano, G.P. \& Verganti, R., 2008. Which kind of collaboration is right for you? Harvard Business Review, December. pp.78-86.

Powell, W.W., Koput, K.W. \& Smith-Doerr, L., 1996. Interorganizational collaboration and the locus of innovation: Networks of learning in biotechnology. Administrative Science Quarterly, 41, pp.116-45.

Provan, K.G. \& Kenis, P., 2008. Modes of Network Governance: Structure, Management, and Effectiveness. Journal of Public Administration Research \& Theory, 18(2), pp.229-52.

Purdy, J.M. \& Gray, B., 2009. Conflicting Logics, Mechanisms of Diffusion, and Multilevel Dynamics in Emerging Institutional Field. Academy of Management Journal, 52(2), pp.355-80.

Pyka, A. \& Küppers, G., 2002. Innovation Networks: Theory and Practice. Cheltenham: Edward Elgar.

Rampersad, G., Quester, P. \& Troshani, I., 2010. Managing innovation networks: Exploratory evidence from ICT, biotechnology and nanotechnology networks. Industrial Marketing Management, 39, pp.793-805.

Ritter, T., 2000. A framework for analyzing interconnectedness of relationships. Industrial Marketing Management, 29, pp.317-26.

Ritter, T. \& Gemünden, H.G., 2003. Network competence: Its impact on innovation success and its antecedents. Journal of Business Research, 56, pp.745-55.

Ritti, R.R. \& Silver, J.H., 1986. Early Processes of Institutionalization: The Dramaturgy of Exchange in Interorganizational Relations. Administrative Science Quarterly, 31(1), pp.25-42.

Ritvala, T. \& Salmi, A., 2010. Value-based network mobilization: A case study of modern environmental networkers. Industrial Marketing Management, 39(6), pp.898-907.

Rowley, T.J. \& Moldoveanu, M., 2003. When will stakeholder groups act? An interest- and identity-based model of stakeholder group mobilization. Academy of Management Review, 28(2), pp.204-19. 
Ryan, A., Tähtinen, J., Vanharanta, M. \& Mainela, T., 2012. Putting Critical Realism to Work in the Study of Business Relationship Processes. Industrial Marketing Management, 41, pp.300-11.

Rycroft, R.W., 2007. Does cooperation absorb complexity? Innovation networks and the speed and spread of complex technological innovation. Technological Forecasting and Social Change, 74(5), pp.565-78.

Rycroft, R.W. \& Kash, D.E., 2004. Self-organizing innovation networks: implications for globalization. Technovation, 24, pp.187-97.

Sayer, A., 1992. Method in social science; a realist approach. London: Routledge.

Scott, W.R., 2008. Institutions and Organizations. Third Edition ed. Thousand Oaks, CA: Sage Publications, Inc.

Seo, M.-G. \& Creed, W.E.D., 2002. Institutional Contradictions, Praxis, and Institutional Change: A Dialectical Perspective. Academy of Management Review, 27(2), pp.222-47.

Shepherd, D.A. \& Sutcliffe, K.M., 2011. Inductive Top-Down Theorizing: A Source of New Theories of Organization. Academy of Management Review, 36(2), pp.361-80.

Siggelkow, N., 2007. Persuasion with case studies. Academy of Management Journal, 50(1), pp.20-24.

Snow, D.A., Soule, S.A. \& Kriesi, H., eds., 2004. The Blackwell Companion to Social Movements. Oxford: Blackwell Publishing.

Stuart, T.E., 2000. Interorganizational alliances and the performance of firms: A study of growth and innovation rates in a high-technology industry. Strategic Management Journal, 21(8), pp.791-811.

Tsoukas, H., 1989. The Validity of Idiographic Research Explanations. Academy of Management Review, 14(4), pp.551-61.

Uzzi, B., 1997. Social Structure and Competition in Interfirm Networks: The Paradox of Embeddedness. Administrative Science Quarterly, 42(1), pp.35-67.

Van Bockhaven, W., Matthyssens, P. \& Vandenbempt, K., 2013. Structural Antecedents of Institutional Entrepreneurship in Industrial Networks: A Critical Realist Explanation. Industrial Marketing Management.

Veal, G. \& Mouzas, S., 2010. Learning to collaborate: a study of business networks. Journal of Business and Industrial Marketing, 25(6), pp.420-34.

von Krogh, G., Rossi-Lamastra, C. \& Haefliger, S., 2012. Phenomenon-based Research in Management and Organisation Science: When is it Rigorous and Does it Matter? Long Range Planning, 45, pp.277-98.

West, J., Vanhaverbeke, W. \& Chesbrough, H., 2006. Open Innovation: A Research Agenda. In H. Chesbrough, W. Vanhaverbeke \& J. West, eds. Open Innovation: Researching a New Paradigm. Oxford: Oxford University Press. pp.285-308.

Yin, R., 1984. Case Study Research. Beverly Hills, CA: Sage Publications.

Zucker, L.G., 1977. The Role of Institutionalization in Cultural Persistence. American Sociological Review, 42(5), pp.726-43.

9. Appendix A: Respondents

\begin{tabular}{|l|l|l|}
\hline & Company description & Contact function \\
\hline Producers & Large global, EU rooted strip products & Business development mgr \\
& Director \\
& Gerch rooted, small EU stainless & Managing director \\
& Mange EU-rooted flat carbon \& steel products & Managing director NL \\
\hline Wholesalers & Global producer factory distribution outlet & Mnit managers \\
& & Director \\
& Mid-large integrated independent distributor* & Managing director the Netherlands \\
& Large EU producer factory outlet & CEO \\
& Large independent multimetal distributor & Managing director \\
& Midsized producer factory outlet & CEO \\
& Regional long \& multiproduct distributor & Marketing director \\
& Midsized independent specialty distributor & Business Unit Manager \\
& Large independent international tube distrib. & CEO \\
& Large indep. Benelux multimetal distrib. & CEO \\
& Large metal sheet \& structures processer & Director \\
& Midsized steel cutting \& finishing center & Marketing manager \\
\hline \multirow{2}{*}{ Jobbers } & Maritime coating \& finishing supplier & \\
\hline
\end{tabular}




\begin{tabular}{|l|l|l|}
\hline $\begin{array}{l}\text { Systems } \\
\text { integrators }\end{array}$ & $\begin{array}{l}\text { Hightech applications \& systems supplier } \\
\text { Hightech precision components \& systems } \\
\text { Offshore component \& systems supplier }\end{array}$ & $\begin{array}{l}\text { Production mgr } \\
\text { Managing director } \\
\text { CEO \& Market intelligence mgr }\end{array}$ \\
\hline OEM & $\begin{array}{l}\text { International steel office furniture OEM } \\
\text { Large diversified steel construction group }\end{array}$ & $\begin{array}{l}\text { Strategic purchaser } \\
\text { CEO }\end{array}$ \\
\hline $\begin{array}{l}\text { Network } \\
\text { federations } \\
\text { \& Industry } \\
\text { associations }\end{array}$ & $\begin{array}{l}\text { Federation Metal Sheet } \\
\text { Society for Surface Treatment of Materials }\end{array}$ & $\begin{array}{l}\text { President } \\
\text { Building with Steel }\end{array}$ \\
$\begin{array}{l}\text { NEVAT, component \& systems association } \\
\text { SFN, wholesellers' trade association }\end{array}$ & $\begin{array}{l}\text { President } \\
\text { President } \\
\text { Branch manager }\end{array}$ \\
\hline
\end{tabular}

*: Independent wholesaler that integrated backward by buying its own production site and forward by combining the knowledge of both activities to develop project capabilities . 